\title{
Case Study of Ground-Based Glaciogenic Seeding of Clouds over the Pyeongchang Region
}

\author{
Ha-Young Yang $\mathbb{D},{ }^{1}$ Ki-Ho Chang $\mathbb{D},{ }^{1}$ Sanghee Chae $\mathbb{D}^{\mathbb{D}},{ }^{1}$ Eunsil Jung, \\ Seongkyu Seo $\mathbb{D},{ }^{1}$ Jin-Yim Jeong $\mathbb{D},{ }^{1}$ Jung-Ho Lee, ${ }^{1}$ Yonghun Ro, ${ }^{1}$ and Baek-Jo Kim ${ }^{1}$ \\ ${ }^{1}$ Applied Meteorology Research Division, National Institute of Meteorological Sciences, Seogwipo 63568, Republic of Korea \\ ${ }^{2}$ School of Constructional Disaster Prevention and Environmental Engineering, Kyungpook National University, \\ Sangju 37224, Republic of Korea \\ Correspondence should be addressed to Ki-Ho Chang; khchang@korea.kr
}

Received 31 August 2017; Revised 23 February 2018; Accepted 15 March 2018; Published 28 May 2018

Academic Editor: István Geresdi

Copyright (C) 2018 Ha-Young Yang et al. This is an open access article distributed under the Creative Commons Attribution License, which permits unrestricted use, distribution, and reproduction in any medium, provided the original work is properly cited.

\begin{abstract}
Ground-based glaciogenic seeding experiments were conducted at the Daegwallyeong Cloud Physics Observation Site (CPOS) from 2012 to 2015 for the target area Yongpyeong, which lies $9 \mathrm{~km}$ away. The preseeding (NOSEED) and seeding (SEED) periods were defined based on the simulation results of AgI concentration $\left(>10 \mathrm{~L}^{-1}\right)$ in the Weather Research and Forecast (WRF) model with the modified Morrison scheme in microphysics. It was difficult to determine whether snow enhancement via seeding occurred over the entire target area due to uncertainties associated with limitations such as observations and numerical model based on only two points (seeding and target sites). However, in three of four cases, the vertical reflectivity from micro rain radar, total concentration, and average size of snow particles observed at PARSIVEL and precipitation increased in the seeding effect time. In two of four cases, the simulated increased precipitation during the seeding effect time was also observed. In one case that did not show changes after seeding, it is analyzed that a sufficient cloud depth was not supplied to the seeding region due to the blocking effect of the Taebaek Mountains.
\end{abstract}

\section{Introduction}

Clouds in the atmosphere are potential water resources; however, only a small proportion of clouds fall as precipitation. To secure water resources, cloud seeding can be used to enhance precipitation and accelerate precipitation efficiency by injecting artificial ice nuclei (IN) or cloud condensation nuclei into targeted clouds [1]. Many studies have been conducted since the first successful field experiment by Schaefer [2]. Experiments on winter snow enhancement through glaciogenic seeding from the upwind side of mountainous areas have shown a high probability of success $[3,4]$.

It is difficult to distinguish between the orographic increase in precipitation and precipitation increased by seeding. Microphysical studies through direct observations using airborne or surface observation may be essential for the verification of the seeding effect. Super and Heimbach
[5] and Super and Boe [6] performed aircraft sampling above the target area after ground-based inserting IN into mountain clouds during winter in the Rocky Mountains. They have shown that ice particle concentration increased in seeded zones compared to control zones. Direct evidences for the changes in precipitation rate, ice crystal habits, and concentration after seeding were confirmed on the ground.

In the silver iodide (AgI) Seeding Cloud Impact Investigation (ASCII) pilot project, Geerts et al. [7] confirmed an increase in radar reflectivity at the boundary layer $(0.5-1.0 \mathrm{~km})$ of mountainous areas during seeding. Pokharel et al. [8] separated upstream (control) and downstream (target) regions based on the location of the AgI generator and defined the preseeding (NOSEED) and seeding (SEED) periods. They confirmed an increase in the radar reflectivity during SEED compared with the NOSEED period.

Ground-based snow enhancement experiments at the Daegwallyeong Cloud Physics Observation Site (CPOS) in 


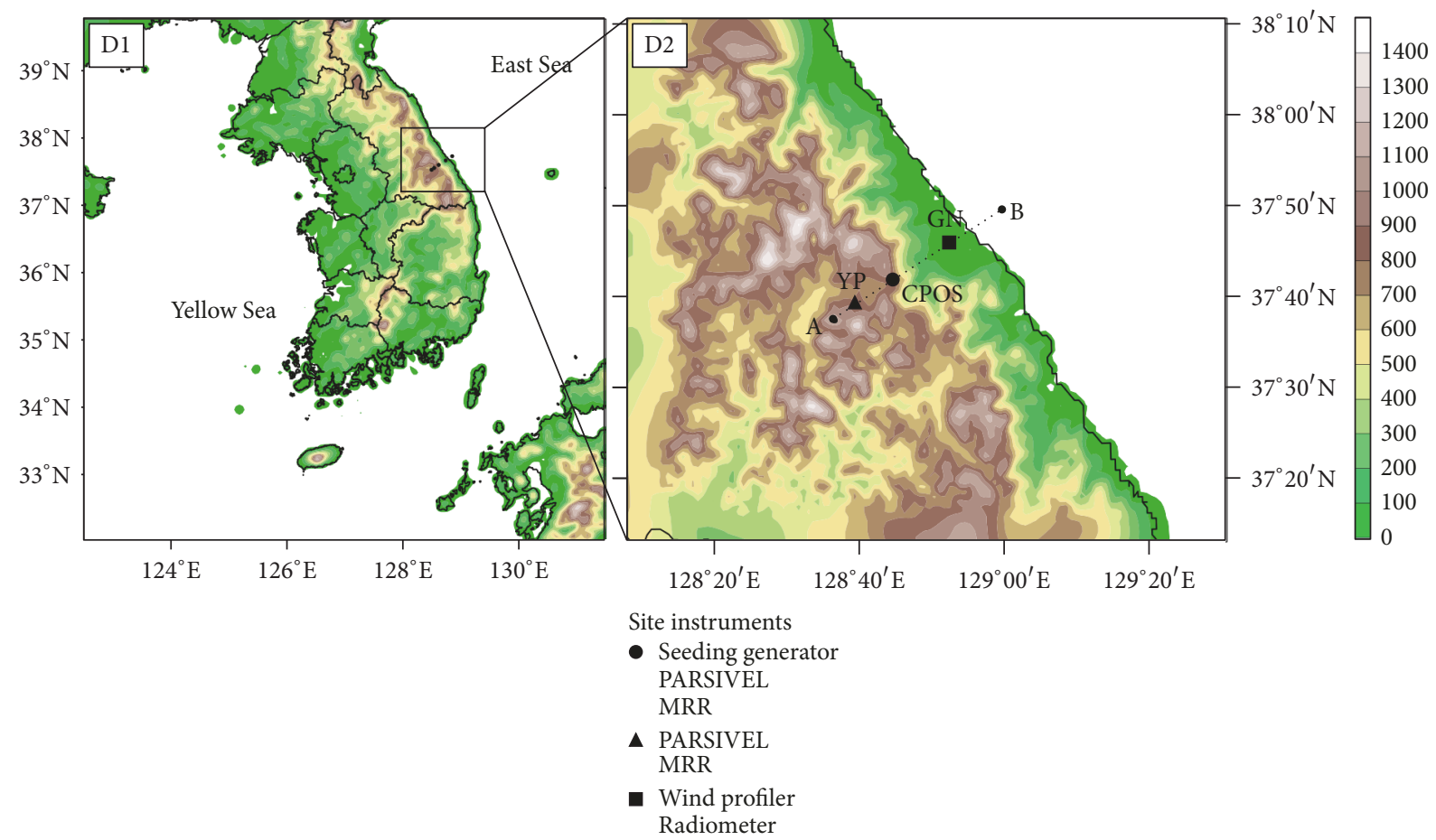

FIGURE 1: The model domain and topography of the experimental region. The triangle, circle, and square indicate the locations of the Yongpyeong observatory (YP), Cloud Physics Observation Site (CPOS), and Gangwon Regional Office of Meteorology (GN), respectively. The dashed line from A to B represents the horizontal cross section passing through YP, CPOS, and GN.

South Korea have been conducted continuously since 2006, targeting Yongpyeong, where the alpine skiing competition of the 2018 Winter Olympics was held. Lee et al. [9] verified an increase in snowfall at CPOS after ground-based AgI seeding in 2006. However, they examined the change in snowfall via rapidly forced condensation processes $(\sim 1 \mathrm{~min})$ at the seeding site CPOS and did not analyze the seeding effects in the downwind target area to show the extension of the seeding effect.

In this study, we examined changes in clouds and precipitation in the downwind target area after ground-based AgI seeding, following the methods of Geerts et al. [7] and Pokharel et al. [8]. But, by the modified WRF (Weather, Research and Forecast) model, the simulated AgI dispersion was used to distinguish the periods unaffected (NOSEED) and affected (SEED) by seeding in the target region. For four seeding experiments, the observed and simulated changes of cloud and surface precipitation during the period between NOSEED and SEED were examined.

\section{Methods}

2.1. Experimental Design. Figure 1 shows the topography of the experimental area and the model domain. The domain for numerical simulations was set to the Korean Peninsula (domain 1, D1) and Gangwon (domain 2, D2), using a twoway grid nesting procedure to simulate D2 more precisely. The CPOS $\left(37^{\circ} 41^{\prime} \mathrm{N}, 128^{\circ} 45^{\prime} \mathrm{E}, 843 \mathrm{~m} \mathrm{MSL}\right)$, which was used as the seeding site, is located on the ridge of the Taebaek Mountain Ranges about $13 \mathrm{~km}$ southwest from the Gangwon
Regional Office of Meteorology (GN, $37^{\circ} 45^{\prime} \mathrm{N}, 128^{\circ} 53^{\prime} \mathrm{E}, 26 \mathrm{~m}$ MSL). The Yongpyeong observatory (YP, $37^{\circ} 38^{\prime} \mathrm{N}, 128^{\circ} 40^{\prime} \mathrm{E}$, $772 \mathrm{~m} \mathrm{MSL}$ ) is about $9 \mathrm{~km}$ southwest from the CPOS. A-B in model domain 2 (D2) stands for a horizontal path of cross section, passing YP, CPOS, and GN. To minimize the possibility of orographic cloud and precipitation enhancement, the target area at YP was designed to be lower than the seeding point CPOS with an altitude difference of $\sim 70 \mathrm{~m}$.

Ground-based AgI seeding experiments were performed at CPOS from 2012 to 2015 by burning the $2 \% \mathrm{AgI}^{-\mathrm{NH}_{4} \mathrm{I}-}$ acetone solution, converting supercooled liquid water into ice crystals. In general, AgI is activated as IN at temperatures of $-5^{\circ} \mathrm{C}$ or lower [10]. However, Blair [11] suggested that the $\mathrm{AgI}-\mathrm{NH}_{4} \mathrm{I}$-acetone solution is activated as IN at warmer temperatures $\left(-3^{\circ} \mathrm{C}\right)$ through a cloud chamber-wind tunnel experiment. Four experimental cases were selected in which, at a low temperature $\left(<-3.5^{\circ} \mathrm{C}\right)$ and under the influence of northeasterly wind at CPOS, the AgI seeding amount was $0.63 \mathrm{~g} \mathrm{~min}^{-1}$, the average liquid water content ( $1 \mathrm{~h}$ before experiment until the end of the experiment) was above $0.1 \mathrm{~g} \mathrm{~m}^{-3}(0.5-1 \mathrm{~km})$ at GN. The observed meteorological information is listed in Table 1. Except for the missing EXP1 data, the average liquid water content at GN (1h before seeding to the start of seeding) was $0.10-0.29 \mathrm{~g} \mathrm{~m}^{-3}$. The height peak CPOS is $843 \mathrm{~m} \mathrm{MSL}$, and thus the LWC of incoming cloud is estimated in the vertical range of $500-1000 \mathrm{~m}$. Stratiform clouds with sufficient liquid water content moved toward CPOS. Easterly winds of $5 \mathrm{~m} \mathrm{~s}^{-1}$ or lower flowed into CPOS during the seeding period, and AgI particles injected 


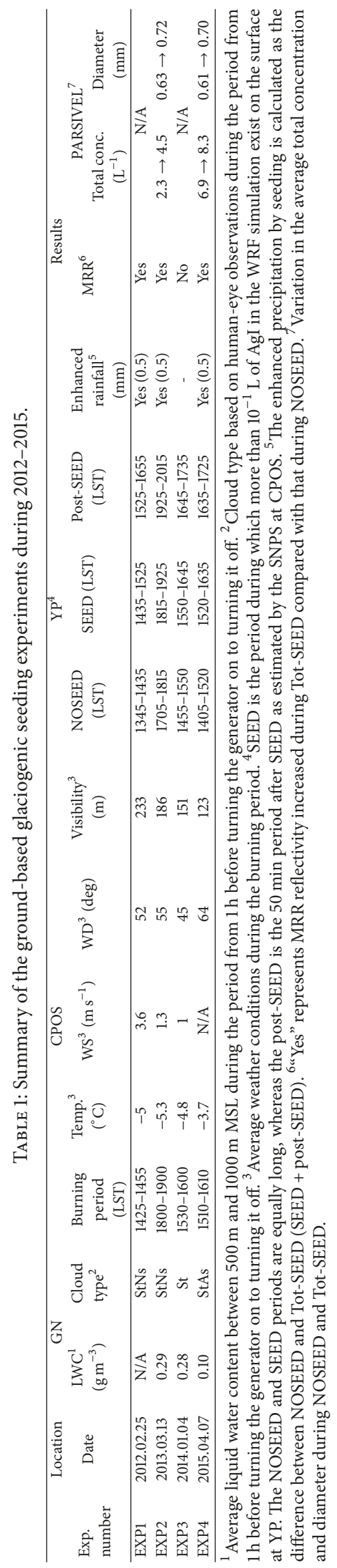


TABLE 2: Summary of model configurations.

\begin{tabular}{|c|c|c|c|c|}
\hline & EXP1 & EXP2 & EXP3 & EXP4 \\
\hline Date & 25 Feb. 2012 & 13 Mar. 2013 & 4 Jan. 2014 & 7 Apr. 2015 \\
\hline Period (LST) & $0900-2100$ & $1200-0000$ & $0900-2100$ & 0900-2100 \\
\hline Domain & & & & \\
\hline Horizontal spacing & & & & \\
\hline Dimension $(x, y, z)$ & & & & \\
\hline Time step (s) & & & & \\
\hline Model top & \multicolumn{4}{|c|}{$50 \mathrm{hPa}$} \\
\hline Grid nesting & \multicolumn{4}{|c|}{ Two-way } \\
\hline Initial \& boundary layer & \multicolumn{4}{|c|}{ KLAPS $(1$ hour, $5 \mathrm{~km} \times 5 \mathrm{~km})$} \\
\hline Microphysics & \multicolumn{4}{|c|}{ Morrison scheme } \\
\hline Planetary boundary layer & \multicolumn{4}{|c|}{ YSU PBL } \\
\hline Land-surface model & \multicolumn{4}{|c|}{ Thermal diffusion scheme } \\
\hline Land use data & \multicolumn{4}{|c|}{ USGS (e.g., topo_30s, soiltype_top_30s) } \\
\hline Longwave radiation scheme & \multicolumn{4}{|c|}{ Rapid Radiative Transfer Model (RRTM) } \\
\hline Shortwave radiation scheme & \multicolumn{4}{|c|}{ Goddard shortwave } \\
\hline
\end{tabular}

directly in the lower clouds (cold fog) with a visibility of $\leq 200 \mathrm{~m}$ at CPOS.

Numerical simulations of the four cases were conducted using the WRF mesoscale model, version 3.4, which is a fully compressible, nonhydrostatic, and primitive equation model [12]. The model configuration is listed in Table 2. The domain D2, used for the analyses of all the experiments, consists of 121 $\times 106$ horizontal grid points with a grid spacing of $1 \mathrm{~km}$ and 40 vertical layers. Initial and boundary conditions for hindcast were set using $1 \mathrm{~h}$ Korea Local Analysis and Prediction System (KLAPS) data with a $5 \mathrm{~km}$ resolution. In this model, the Morrison microphysics scheme was modified to include the actual AgI release at a chosen surface point and ice nucleation process. A detailed description of the ice nucleation process is provided by Kim et al. [13] and Chae et al. [14].

2.2. Instruments. Several instruments were used both upwind and downwind of CPOS. Lee et al. [9] mentioned the importance of humidity in the upwind area as a factor influencing the seeding effect at CPOS. To examine the upwind weather conditions before the seeding, wind profiler (PCL1300, Degreane Horizon) and microwave radiometer (MWR; RPG-HATPRO, Radiometer Physics GmbH) data at GN were used. The wind profiler observes the upperair wind speed and direction with high vertical resolutions by performing observations every $10 \mathrm{~min}$ [15]. The MWR receives microwave signals in 14 frequency bands from the atmosphere and represents measurements of brightness temperature. It may produce the sounding of temperature, humidity, water vapor amount, and liquid water content data.

At the seeding point CPOS, changes in weather conditions and aerosol due to seeding were observed with an automatic weather station (AWS, Vaisala) at $15 \mathrm{~m}$ above ground level and a scanning nanoparticle spectrometer
(SNPS; HCTm), respectively, throughout the experiment. The SNPS is connected to a differential mobility analyzer and condensation particle counter and measures the size distribution of 7-282 $\mathrm{nm}$ particles. At YP, which is in the downwind area, observation data from the micro rain radar (MRR; Metek) and a PARSIVEL disdrometer (PARSIVEL; OTT Hydromet) were used. Snow depth was not observed during the experimental period; therefore, the precipitation data obtained using a $0.5 \mathrm{~mm}$ tipping-bucket rain gauge (JY100097-2; Jinyang) were used for verification. The rain gauge for measuring the snowfall has a time delay of around 20 min due to internal heating (communication with GN). The PARSIVEL is a laser-based optical sensor used for the simultaneous measurement of liquid and solid precipitation particles $[16,17]$. The MRR retrieves quantitative rain rate, drop size distribution, radar reflectivity, fall velocity of hydrometeors, and other rain parameters simultaneously on vertical profiles up to several kilometers above the radar [18]. To use the MRR data for snow observations, Maahn and Kollias [19] regarded the main signals from the Doppler power spectrum of raw data as the Doppler speed by snow and calculated the equivalent reflectivity after noise removal and dealiasing. In this study, we analyzed the reproduced data following their proposed MRR processing method.

\section{Results}

3.1. Description of Cases. Figure 2 shows the synoptic weather situation of the four cases from the Korea Meteorological Administration (KMA) website. At CPOS, air parcels in the seeding experiments move from the East Sea and frequent low clouds and fog occur because it is close to the east coast and there are steep slopes to the east [20]. When the synoptic chart over the Korean Peninsula is of a northern high 


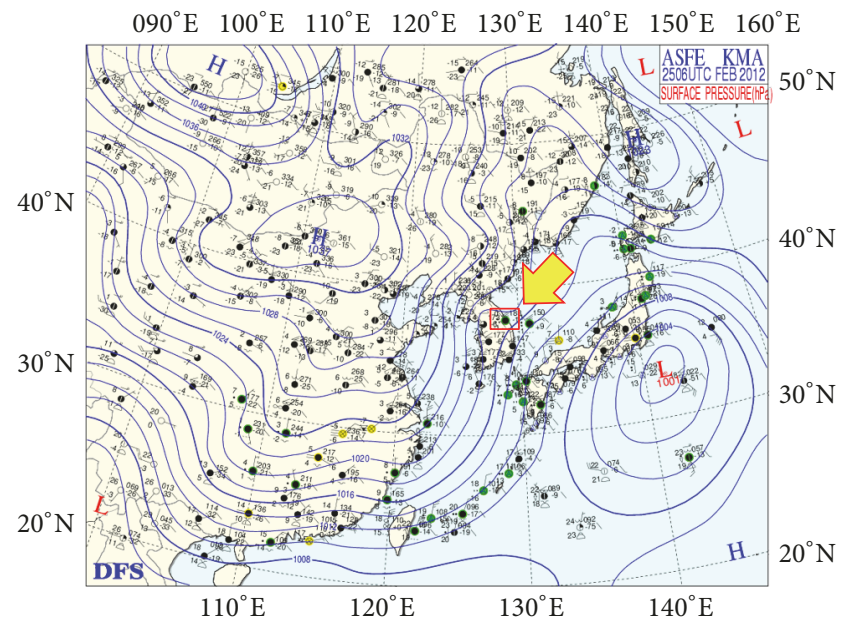

(a) 25 Feb. 20121500 LST (EXP1)

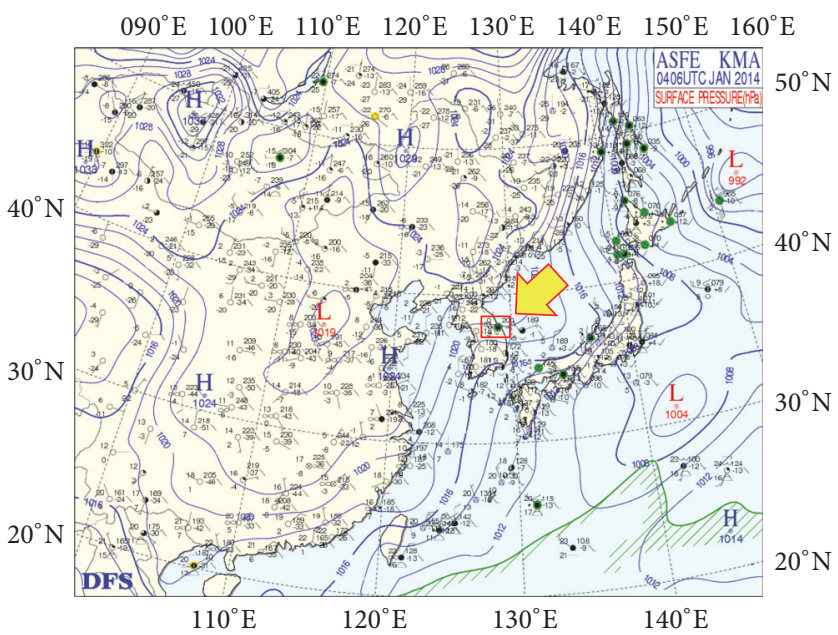

(c) 4 Jan. 20141500 LST (EXP3)

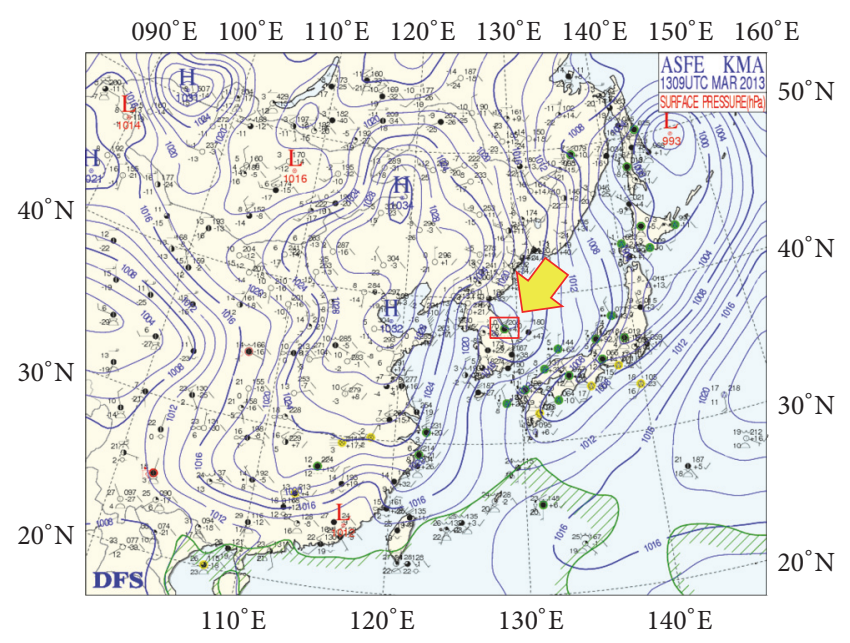

(b) 13 Mar. 20131800 LST (EXP2)

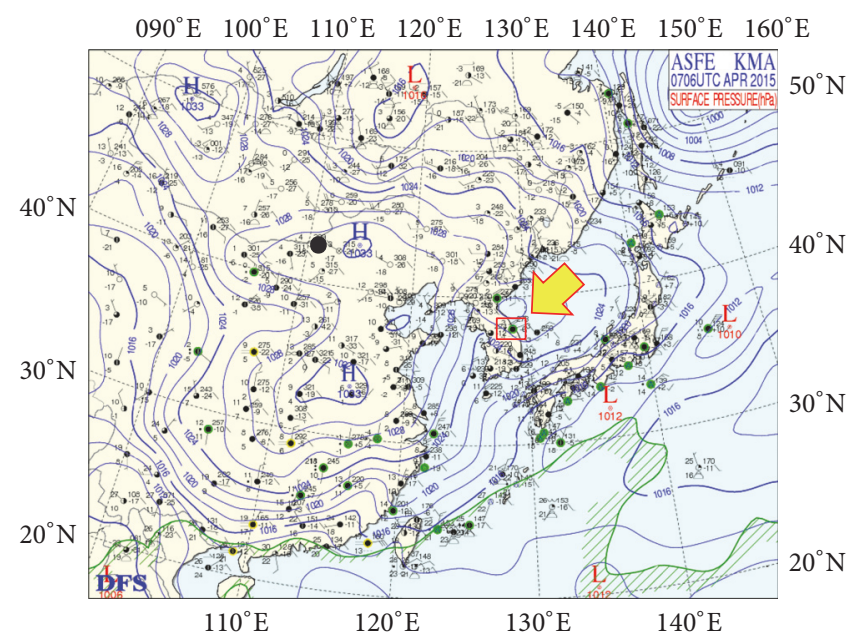

(d) 7 Apr. 20151500 LST (EXP4)

FIGURE 2: Synoptic weather charts for (a) EXP1, (b) EXP2, (c) EXP3, and (d) EXP4. The red box indicates the experimental region shown in Figure 1.

and southern low type, the long period of fog (low clouds) often occurs in the Daegwallyeong area due to the northeast airflow. This fog is effective for experiments of direct seeding into clouds because it moves upward via advection along the steep mountain of the Taebaek Mountain Ranges and flows into Daegwallyeong in a supercooled condition [21-23].

The EXP1 case exhibits a cold advection pattern (CA) with a typical high-west-low-east pressure pattern due to the effects of the migratory anticyclone in China and the trough in the Yeongdong region, South Korea, and northeasterly wind flows into the Yeongdong region (Figure 2(a)). Lee [24] confirmed that, in CA, the cold advection via northeasterly winds results in precipitation in the Yeongdong region in general. The EXP2, EXP3, and EXP4 cases exhibit the lowpressure patterns (LPs) that passed along the Japanese islands resulting in easterly airflow into the Taebaek mountains (Figures 2(b)-2(d)). In the LPs, an easterly wind with high humidity lasting for 1-2 days produced easterly orographic low clouds in the Daegwallyeong region.

3.2. Simulated Results. We compared the simulated and observed precipitation to verify the performance of the WRF model. Figure 3 illustrates the $12 \mathrm{~h}$ accumulated simulated and observed precipitation over the simulation period of each case. In most cases, the simulated precipitation is slightly underestimated in the coastal area, overestimated in the mountainous area. However, the simulated precipitation pattern was reasonably consistent with the observations.

Figure 4 shows vertical cross sections of the AgI particle concentration, cloud water mixing ratio, temperature, and wind vectors at the $30 \mathrm{~min}$ after the AgI generator was turned on. AgI diffuses toward YP in all simulations. Cloud water mixing ratio more than $0.1 \mathrm{~g} \mathrm{~kg}^{-1}$ was simulated above CPOS for all the cases, and northeasterly winds of 7-10 $\mathrm{m} \mathrm{s}^{-1}$ from CPOS to $1.5-2.0 \mathrm{~km}$ MSL were simulated from the CPOS 


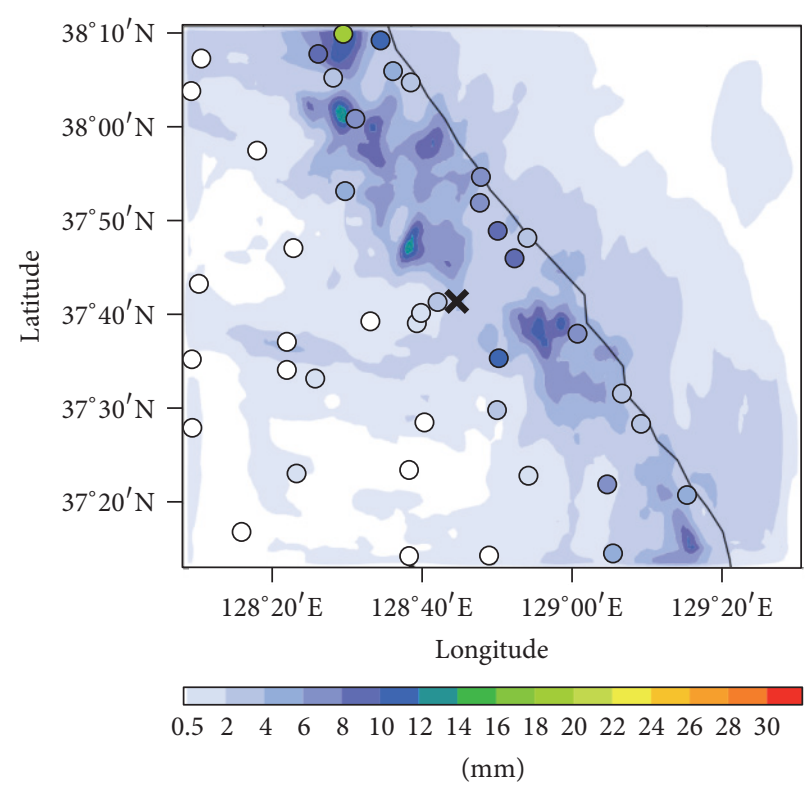

(a)

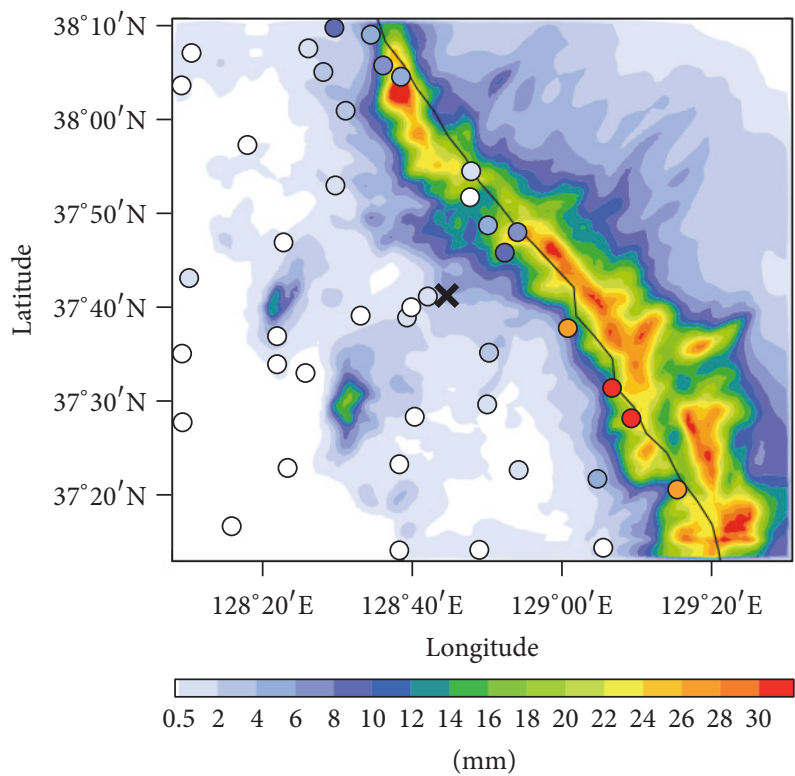

(c)

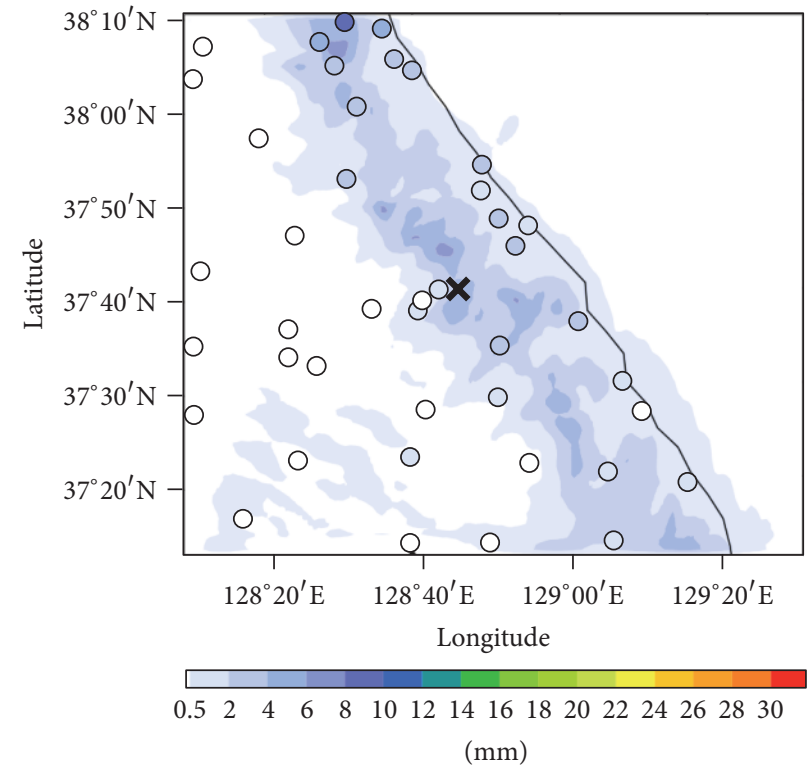

(b)

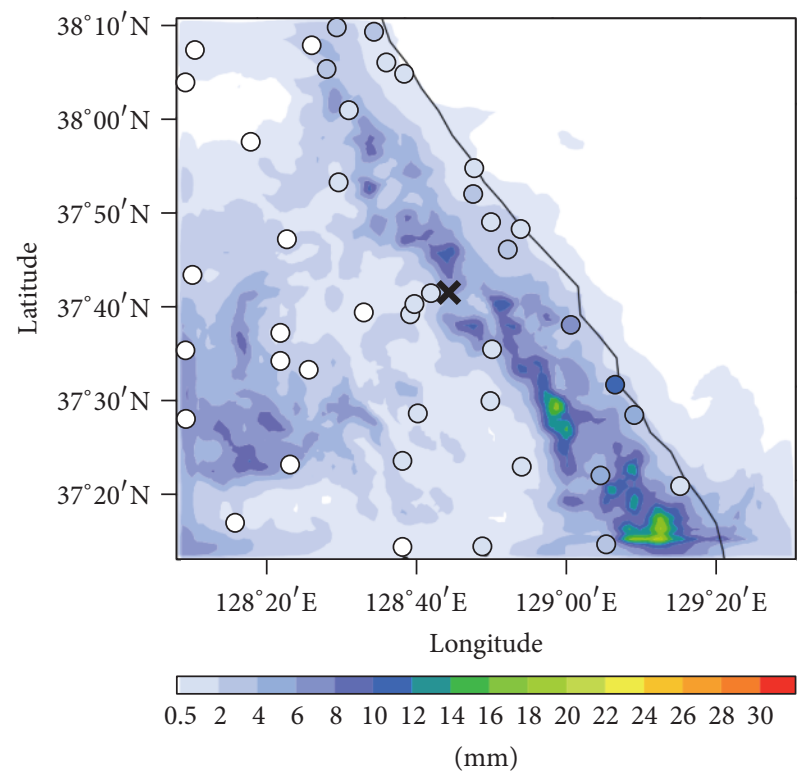

(d)

FIGURE 3: The $12 \mathrm{~h}$ accumulated precipitation ( $\mathrm{mm}$ ) of nonseeded simulation and rain gauges for (a) EXP1, (b) EXP2, (c) EXP3, and (d) EXP4. The simulated precipitation is color shaded, overlaid by the rain gauge precipitation in color-filled circles. The cross indicates the location of CPOS.

to YP in EXP1, EXP2, and EXP4. In EXP3, the relatively low wind speed of $5 \mathrm{~m} \mathrm{~s}^{-1}$ was simulated. The $9 \mathrm{~h}$ simulated vertical wind by this model for $1.5-2.0 \mathrm{~km}$ MSL at CPOS showed agreement with the observed wind by radiosonde at 1800 LST, 13 March 2013 [20]. Compared with the simulated mean wind speed for 1.5-2.0 km MSL at CPOS, the observed surface wind speed appears to be relatively very weak (Table 1) due to the roughness of mountain forests.

Under natural conditions, IN exists less than $1 \mathrm{~L}^{-1}$ [7]. The SEED period was defined in accordance with the simulation results of the AgI concentration $\left(>10 \mathrm{~L}^{-1}\right)$ at the surface of YP. This value was arbitrarily chosen value in the seeding simulation to induce some difference from the natural value. A period of the same duration as the SEED period before seeding was defined as NOSEED. Figure 5 shows the temporal behavior and residue of aerosol particles after seeding at CPOS. During the background measurements at CPOS, the accumulation mode was predominant, with a mean particle size of $110 \mathrm{~nm}$. After the AgI generator was turned on at 1510 LST, aerosols of $10-100 \mathrm{~nm}$ were generated, and the total 

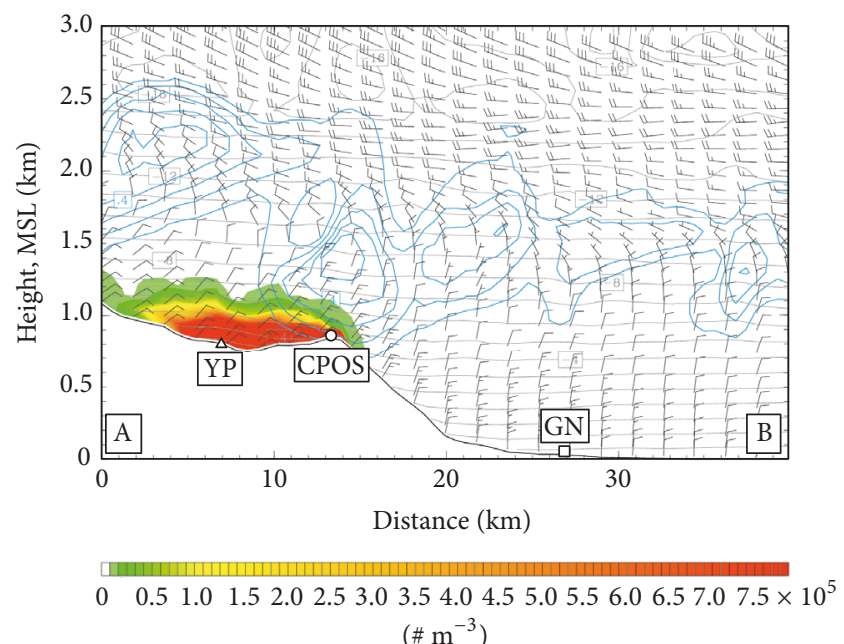

(a) 25 Feb. 20121455 LST (EXP1)

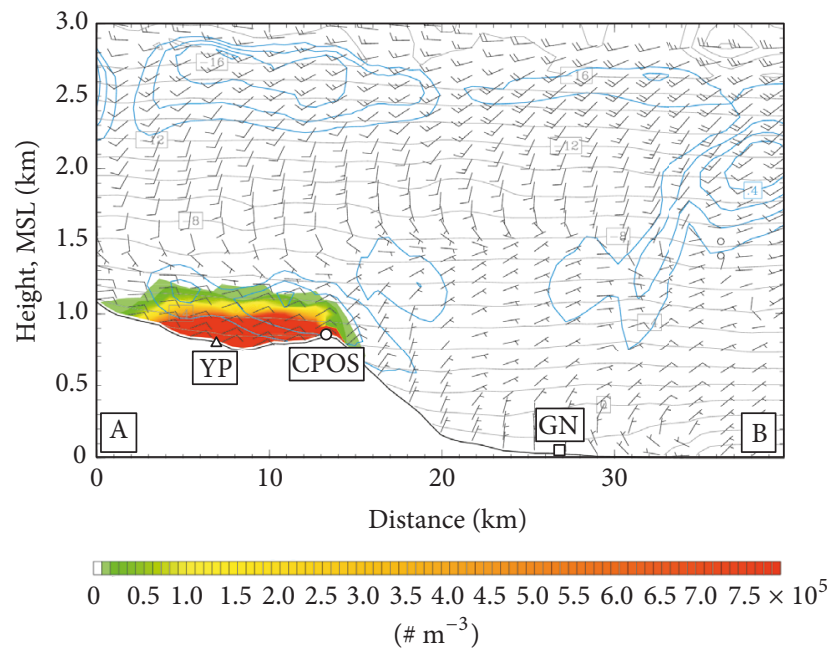

(c) 4 Jan. 20141600 LST (EXP3)
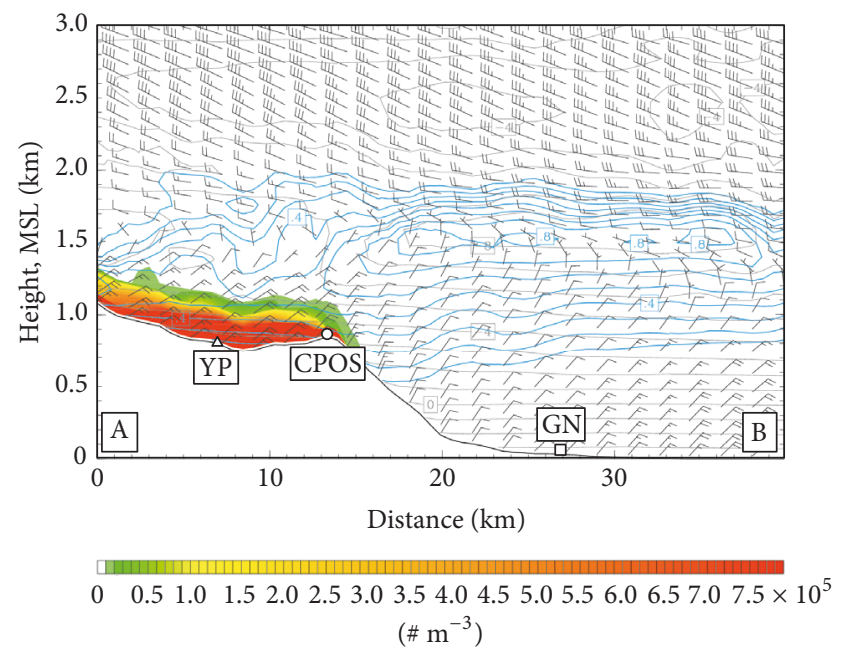

(b) 13 Mar. 20131830 LST (EXP2)

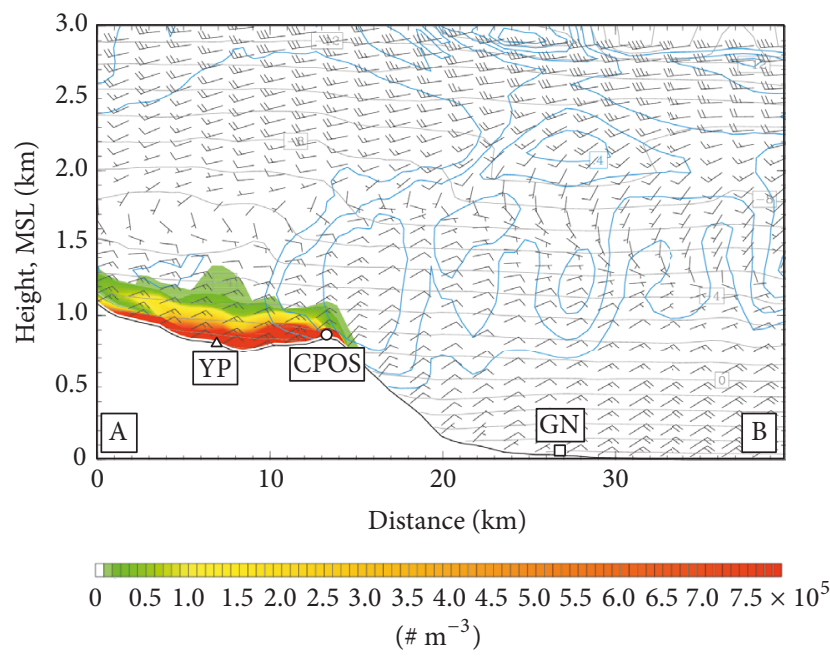

(d) 7 Apr. 20151540 LST (EXP4)

FIgURE 4: Vertical cross sections of the AgI particle number concentration (color shaded, $\mathrm{m}^{-3}$ ), cloud water mixing ratio (blue solid line, $\mathrm{g} \mathrm{kg}^{-1}$ ), temperature (grey solid line, ${ }^{\circ} \mathrm{C}$ ), and wind vectors at 30 min after seeding simulated by the WRF model. The A-B line is the same as shown in Figure 1.

concentration of aerosols increased to $22,000 \mathrm{~cm}^{-3}$, reaching a maximum for particles around $40 \mathrm{~nm}$. According to the results of Vali et al. [25], the dry $\mathrm{AgI}-\mathrm{NH}_{4} \mathrm{I}$ solution has a size range of $0.01-10 \mu \mathrm{m}$, and most aerosols exist in the range of 5-50 nm. Therefore, most of the aerosols observed after seeding seems to be the AgI particles. The particle concentrations steadily decreased after the generator was turned off and then returned to a similar state as the preseeding state at approximately $50 \mathrm{~min}$ after the end of seeding. The residue time (post-SEED) after the end of seeding was assumed as 50 min for all the experimental cases. It was assumed that the air mass moving toward YP was affected because the seeding material at CPOS exerted an influence until 50 min after the end of seeding (Figure 5). Therefore, 50 min after the SEED period was defined as the post-SEED period, and the total section affected by seeding was defined as Tot-SEED (SEED + post-SEED).
3.3. Vertical Reflectivity and Precipitation. Figure 6 shows the $10 \mathrm{~min}$ accumulated precipitation from the $0.5 \mathrm{~mm}$ tippingbucket rain gauge and the vertical reflectivity from the MRR at YP. The quality control method proposed by Maahn and Kollias [19] removes noise up to the second observation bin $(400 \mathrm{~m})$. In Figure 6, the increase in vertical reflectivity was well shown in Tot-SEED compared with that in NOSEED especially for EXP1, EXP2, and EXP4. During NOSEED ( $\sim 1400 \mathrm{LST})$, the reflectivity of $0-5 \mathrm{dBZ}$ appeared intermittently at altitudes below $1 \mathrm{~km}$ (Figure 6(a)). However, in TotSEED, the reflectivity of 5-15 dBZ appeared homogeneously from the ground up to around $1.5 \mathrm{~km}$. In the cases of EXP2 and EXP4, no reflectivity was detected via MRR for NOSEED, but reflectivity was observed for Tot-SEED.

In the cases of EXP1 and EXP4, a $0.5 \mathrm{~mm}$ increase in precipitation was observed during post-SEED. However, in the case of EXP3, vertical reflectivity showed no significant 


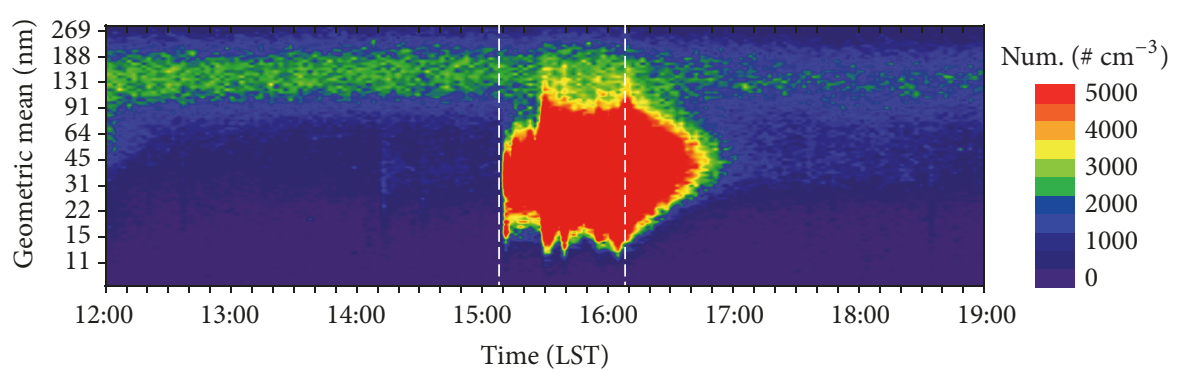

(a)

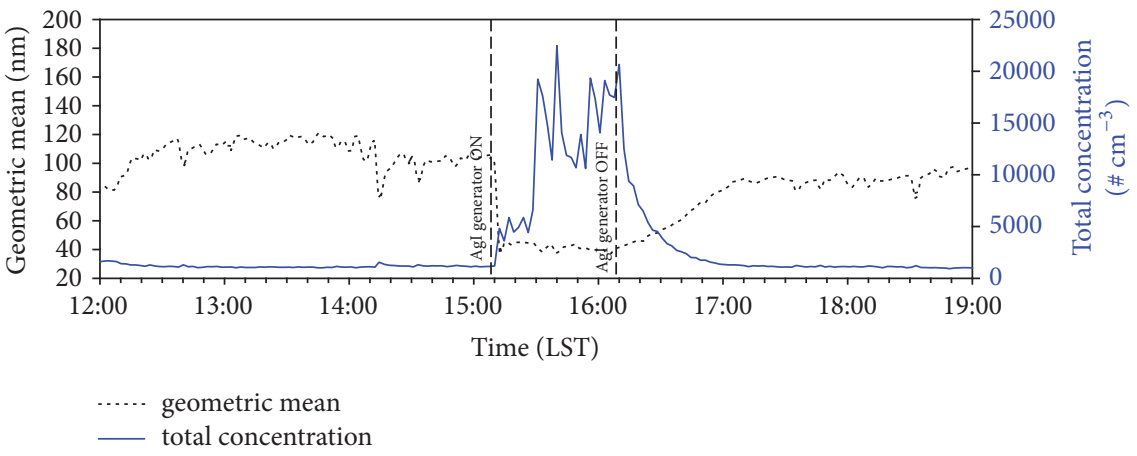

(b)

FIGURE 5: Distribution of the (a) particle number concentrations with geometric size and (b) time series of the geometric mean (dotted) and total particle number concentrations (solid) of aerosols measured by SNPS at CPOS on 7 Apr. 2015. The dashed lines represent the seeding period.

changes and no precipitation was observed in NOSEED and Tot-SEED. In addition, there was a difference in the reaction time of the seeding effect at YP that corresponded to the downwind side depending on the wind speed at CPOS (Figure 6). For example, the surface wind speeds at CPOS for EXP1 and EXP2 were $3.6 \mathrm{~m} \mathrm{~s}^{-1}$ and $1.3 \mathrm{~m} \mathrm{~s}^{-1}$, respectively. Therefore, EXP1 is believed to show more rapid precipitation enhancement more rapidly than the other cases. We assumed that the starting time of snowfall at YP was earlier than the detection of precipitation due to the delay in the snow melting time (estimated as about $20 \mathrm{~min}$ ) in the rain gauge. In Figures 6(a) and 6(d), we believe that the precipitation appears later than the reflectivity due to this delay. On the other hand, in the case of EXP3, the vertical reflectivity showed no significant changes and no precipitation was observed in NOSEED or Tot-SEED (Figure 6(c)).

In the cases of EXP2, the precipitation of $0.5 \mathrm{~mm}$ occurred during post-SEED, but the increased reflective was smaller than other cases. For the EXP1 and EXP2, the difference of the seeded and nonseeded simulated precipitations was well appeared near the YP target area (Figure 7). In case of EXP4, an increase in reflectivity and precipitation was observed, but the increase in precipitation in the model by seeding was not shown. Figure 4(d) shows that the simulated temperature near the minimum optimal concentration for ice nucleation $\left(\sim 10^{-5} \mathrm{~m}^{-3}\right)$, proposed by Xue et al. [26], in the middle between YP and CPOS is about $-2.5^{\circ} \mathrm{C}$, which is lower than the minimum temperature for ice nucleation $\left(-4^{\circ} \mathrm{C}\right)$.
Therefore, we guess that the condition for the ice nucleation is insufficient in the simulation for EXP4 (Figure 7(d)).

To examine the vertical cloud changes before and after seeding, the difference in the frequency-by-altitude diagram (FAD) was calculated following the methods of Yuter and Houze [27] and Pokharel et al. [28]. These diagrams show the normalized frequency of vertical reflectivity by height. The difference FAD for the MRR vertical reflectivity composited during Tot-SEED and NOSEED is shown in Figure 8. The FAD difference analysis was not performed for EXP2 and EXP4 because no reflectivity was observed in NOSEED. In the case of EXP1, the reflectivity increased up to around $1.5 \mathrm{~km}$ and about $2 \mathrm{dBZ}$ on the ground (Figure $8(\mathrm{a})$ ). However, in the case of EXP3, the average reflectivity change between NOSEED and Tot-SEED is very small, lower than $0.5 \mathrm{dBZ}$, indicating that seeding had no significant effect (Figure 8(b)).

Figure 9 shows the vertical wind field observed by the wind profiler at GN. The dashed line indicates the height of wind change from east $\left(0-135^{\circ}\right)$ to west $\left(225-360^{\circ}\right)$. The altitudes at which the wind field changed one hour before the start of seeding in EXP1, EXP2, EXP3, and EXP4 were $1.6 \mathrm{~km}, 1.3 \mathrm{~km}, 0.9 \mathrm{~km}$, and $1.2 \mathrm{~km}$, respectively. In EXP3 (Figure 9(c)), in which there was no increase in precipitation at YP, the thickness of the cloud layer flowing to the seeding point appeared to be relatively thinner because the mountain (the height of peak is about $840 \mathrm{~m}$ ) blocked the supply of sufficient liquid water (by simple calculation, the easterly cloud 


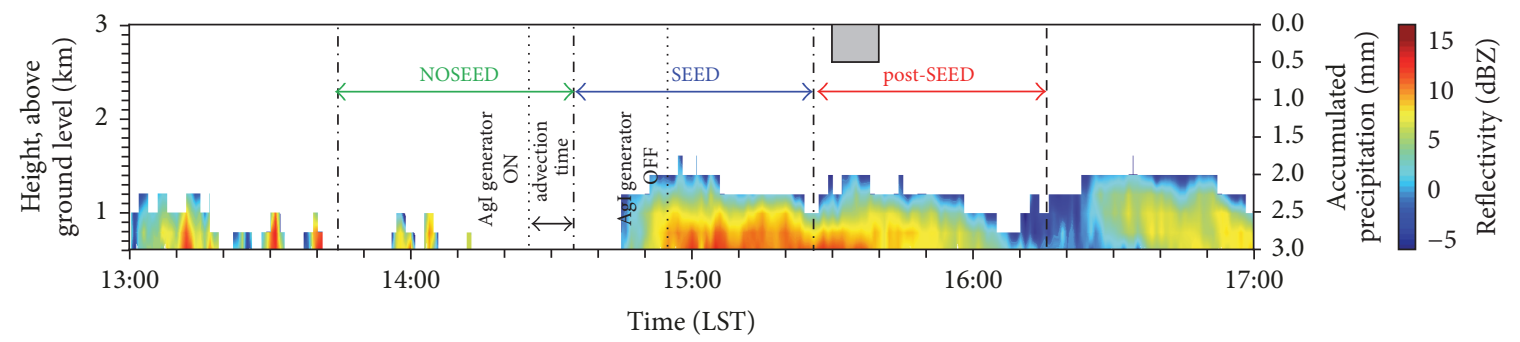

(a)

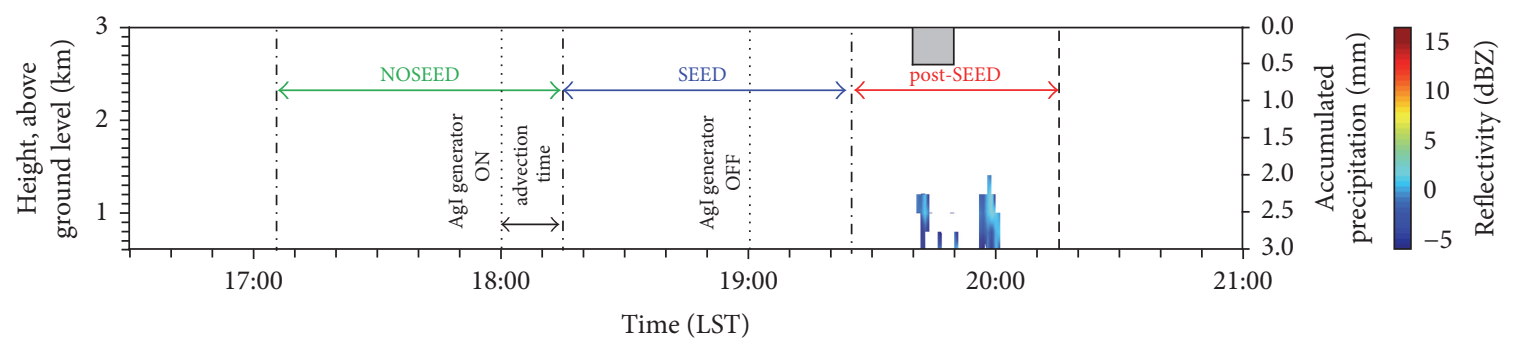

(b)

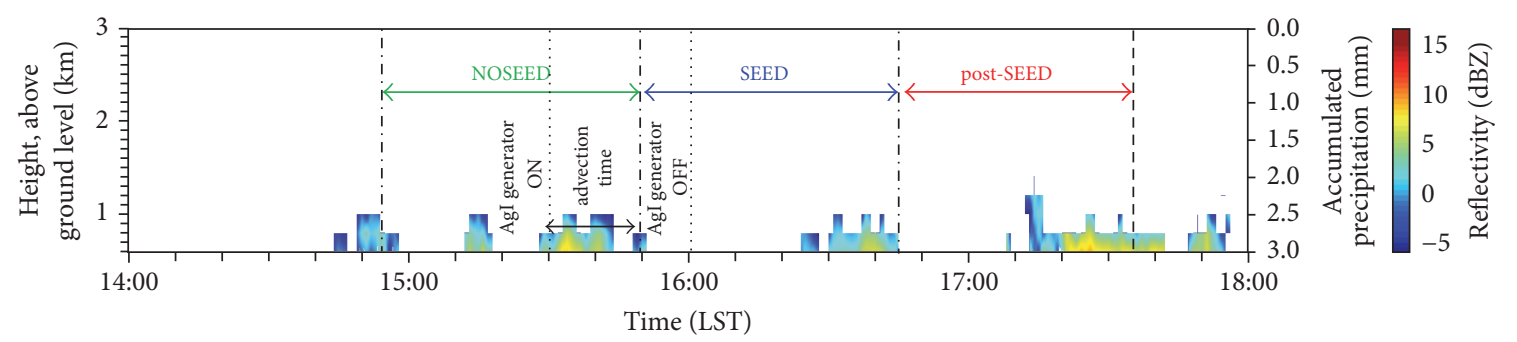

(c)

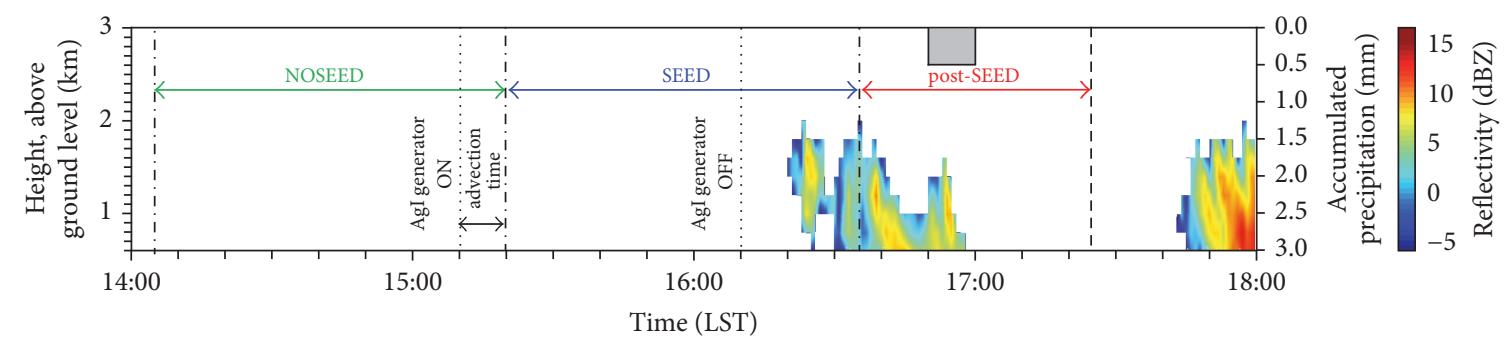

(d)

FIGURE 6: Time series of vertical reflectivity measured by micro rain radar (MRR, color shaded) and 10 min accumulated precipitation (grey bar) from the rain gauge at YP for (a) EXP1, (b) EXP2, (c) EXP3, and (d) EXP4.

thickness may be estimated as $60 \mathrm{~m}$, the difference between the height of mountain peak and changed wind field).

To investigate whether the inflow of natural precipitation into YP was the cause of the increased reflectivity of TotSEED, $1 \mathrm{~h}$ averaged radar reflectivity of PPI0 after the start of seeding was examined (Figure 10). Radar reflectivity was not shown in the target area during the Tot-SEED period for EXP2, EXP 3, and EXP4. For the EXP1, the reflectivity at YP is small $(-2-0 \mathrm{dBZ})$.

3.4. Changes in Snow Particles. We investigated microphysical changes such as number concentration and particle size before and after seeding using PARSIVEL data as in the ASCII study [28-30]. PARSIVEL observes snow particles between $0.062 \mathrm{~mm}$ and $25.5 \mathrm{~mm}$ with 32 size bins. Figure 11 shows the total snow concentration and mean diameter for EXP2 and EXP4 from PARSIVEL at YP. EXP1 and EXP3 were excluded from this analysis because of missing measurements. In EXP2 (Figure 11(a)), the snow particle number concentration rapidly increased from 1810 LST to 1830 LST. Although the average snow particle number concentration observed by PARSIVEL from 1630 LST to 1750 LST at CPOS (the seeding point) was below $5 \mathrm{~L}^{-1}$, it increased sharply to over $15 \mathrm{~L}^{-1}$ from 1750 LST to 1820 LST before the start of seeding (not 


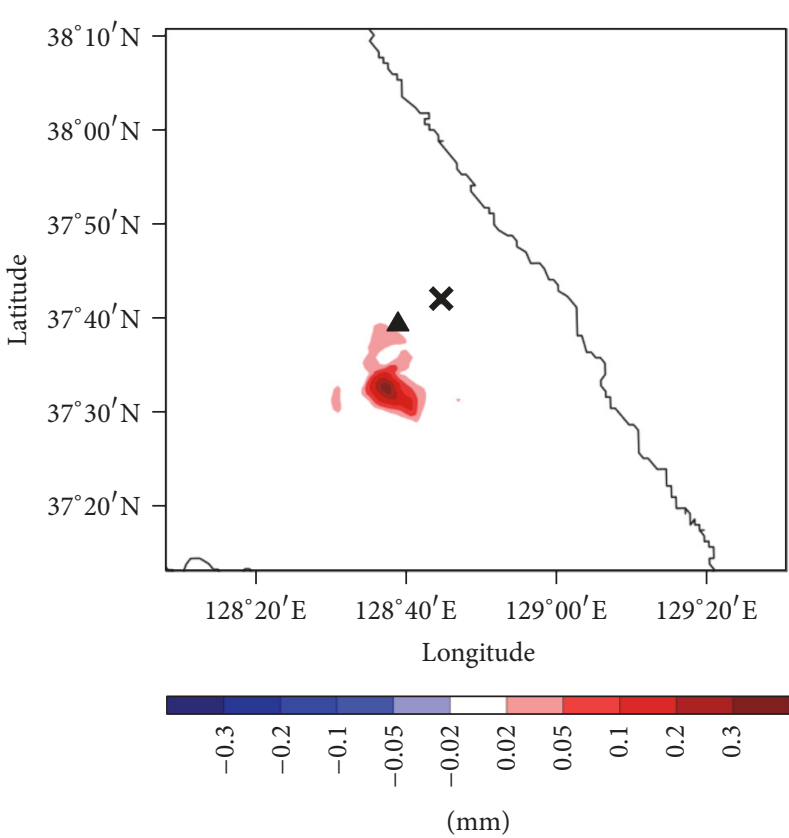

(a) 1630 LST (EXP1)

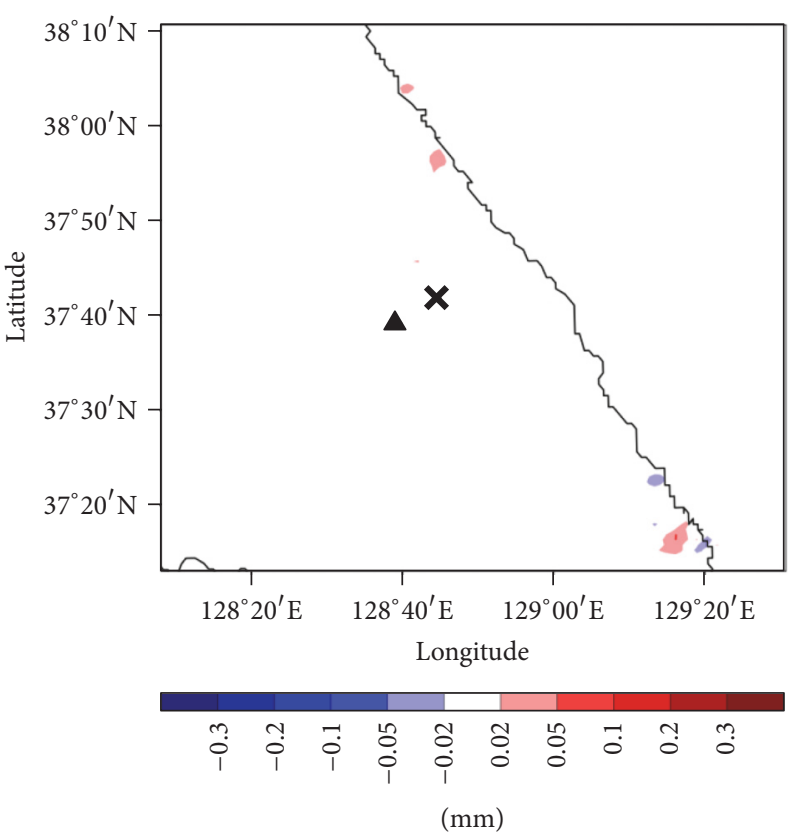

(c) 1730 LST (EXP3)

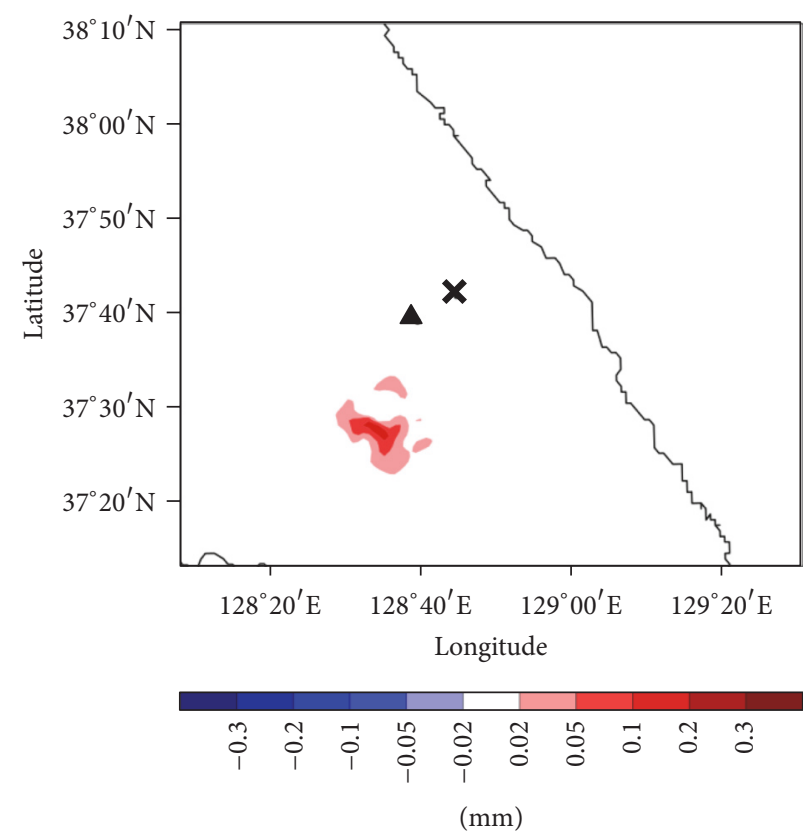

(b) 2030 LST (EXP2)
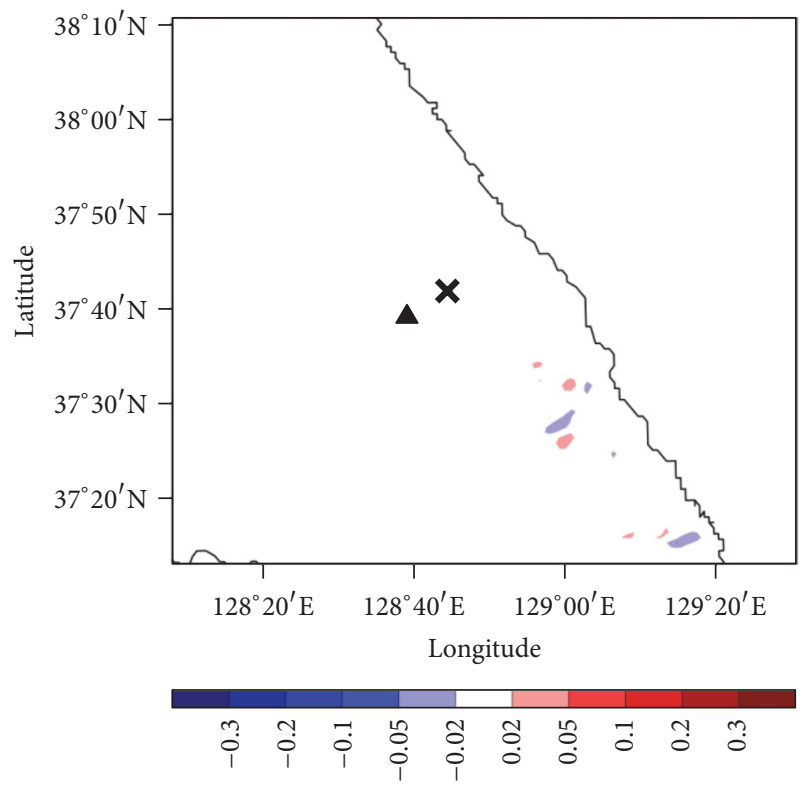

$(\mathrm{mm})$

(d) 1730 LST (EXP4)

FIGURE 7: Differences between the accumulated seeded and nonseeded precipitation $(\mathrm{mm})$ during the period from the start of seeding to the end of post-SEED. The triangle and cross indicate the locations of YP and CPOS, respectively.

shown). Therefore, the period from 1810 LST to 1830 LST when the number concentration at YP increased sharply was excluded from this analysis, considering that the change was not caused by seeding but by a temporary inflow of natural precipitation from CPOS. In the case of EXP2 (Table 1), the mean diameter of Tot-SEED increased from $0.63 \mathrm{~mm}$ to $0.72 \mathrm{~mm}$ compared to NOSEED, and the total snow particle concentration increased by 1.9 times from $2.3 \mathrm{~L}^{-1}$ to $4.5 \mathrm{~L}^{-1}$. In EXP4 (Figure 11(b)), the average particle size increased from $0.61 \mathrm{~mm}$ to $0.70 \mathrm{~mm}$ and the particle number concentration increased by 1.2 times from $6.9 \mathrm{~L}^{-1}$ to $8.3 \mathrm{~L}^{-1}$ in Tot-SEED compared to NOSEED.

In the ASCII project, the total snow concentration was below $0.5 \mathrm{~L}^{-1}$ during NOSEED but increased to $2-15 \mathrm{~L}^{-1}$ during SEED, and a high particle number concentration was maintained even in the post-SEED period. The project suggested that the continuous increase in snow particles during the post-SEED period was caused by a delayed impact 


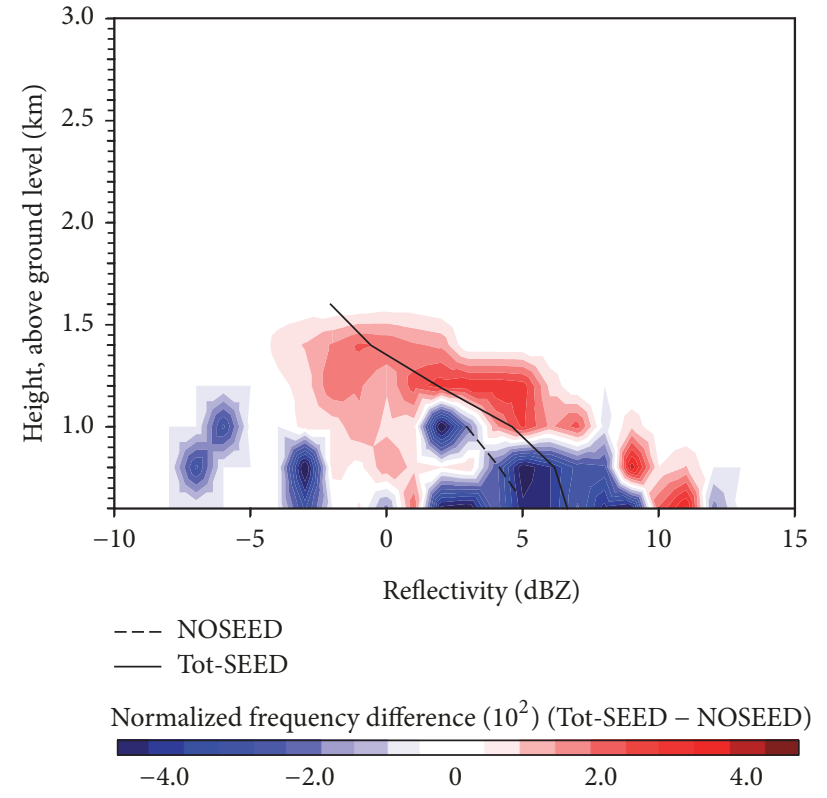

(a)

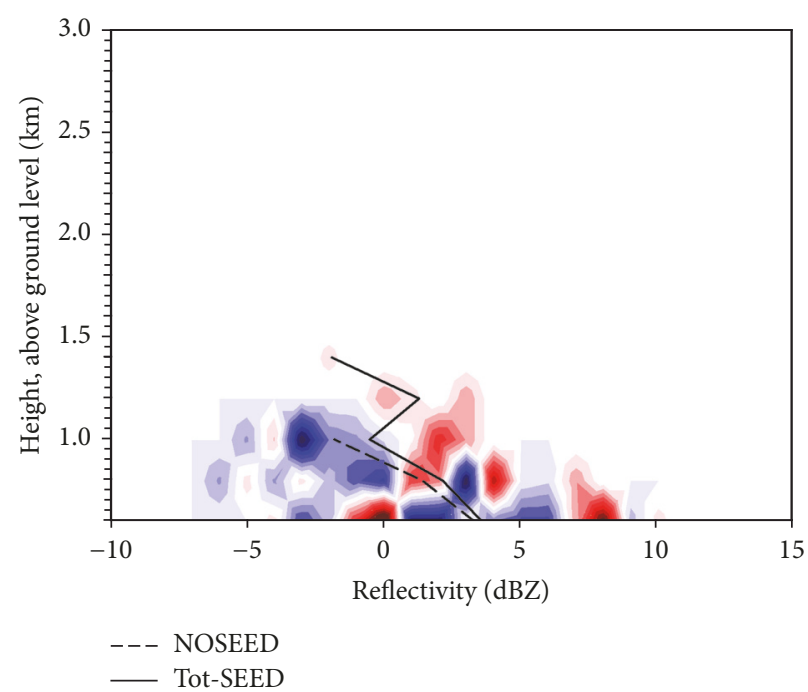

Normalized frequency difference $\left(10^{2}\right)$ (Tot-SEED - NOSEED)

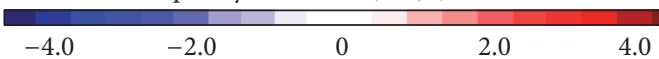

(b)

FIGURE 8: Normalized frequency difference from the MRR between NOSEED (dashed) and Tot-SEED (solid) at YP for (a) EXP1 and (b) EXP3.

due to the slow mixing of AgI nuclei in the clouds, the low transport speed, and the slow nucleation rate following the AgI nuclei seeding at the $300 \mathrm{~m}$ cloud base. This study also showed that the mean diameter and particle number concentration increased during post-SEED compared to SEED. The simulated AgI dispersion was faster than the wind speed at the same altitude observed with the wind profiler at GN. The relatively large increase of snow particles during the post-SEED appears to be partially due to the earlier simulated end time of SEED.

The particle size distribution data from PARSIVEL are grouped into two parts corresponding with the NOSEED and Tot-SEED. Figure 12 shows differences in the normalized frequency-by-diameter displays for NOSEED and Tot-SEED at YP based on the method of Pokharel et al. [28]. Compared with NOSEED, both large and small particles increased markedly during Tot-SEED. This indicates the effect of seeding, similar to the results of previous studies [30-32].

\section{Conclusions and Discussions}

In this study, experimental cases from 2012 to 2015 were analyzed to investigate the effects of ground-based AgI seeding on clouds over Pyeongchang region. At YP, the target area downwind of the seeding site (i.e., CPOS), the vertical reflectivity based on MRR increased at altitudes below $1 \mathrm{~km}$ during the Tot-SEED period, when the cloud thickness was sufficient. In those cases, the total snow particle number concentration and mean size measured by PARSIVEL also increased after seeding. In all the cases, the $1 \mathrm{~h}$ averaged composite reflectivity of grounded scanning radar was absent or negligible after seeding, and thus the inflow of natural precipitation into YP appeared to be low. As a result, the precipitation increase in Tot-SEED could be attributed to the seeding effect in EXP1, EXP2, and EXP4. The precipitation enhancement is well shown in the simulation by the WRF with the modified Morrison scheme in microphysics seeding effect, especially for EXP1 and EXP2. In the case (EXP3) without any change after seeding, the cloud layer was thinner than the other cases, sufficient liquid water content was not supplied to the seeding area. This is due to the small vertical extent of the easterly wind field, thus showing almost no seeding effect.

There were uncertainties associated with the results. First, the simulated dispersion time of AgI used to define the NOSEED and SEED periods was slightly (below $30 \mathrm{~min}$ ) faster than the time estimated by the advection with the observed wind speed from wind profiler at GN. However, because we used the same numerical model as that used by Kim et al. [13], it was assumed that the dispersion time of the seeding material was valid in this study.

Second, the inflow of natural precipitation was uncertain. Only the $1 \mathrm{~h}$ averaged PPI0 of the composite reflectivity data was used to determine the inflow of natural precipitation. Therefore, the inflow of natural precipitation could not be excluded completely in each case, especially below $1.5 \mathrm{~km}$. Consequently, the increases in reflectivity, precipitation particle size, and particle number concentration that appeared after seeding could not be clearly attributed to the seeding effect. Furthermore, it is difficult to assert that the snow enhancement due to seeding existed in the entire Yongpyeong area due to uncertainties in the observations and numerical model. However, there were many seeding effects such as the 


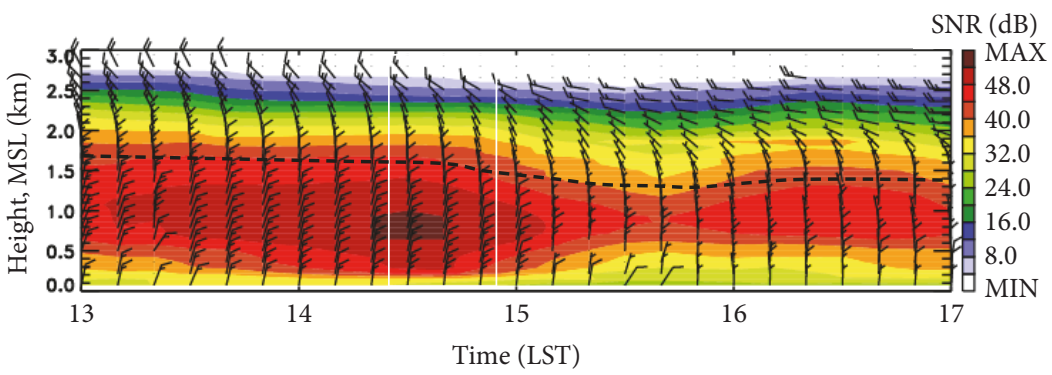

(a)

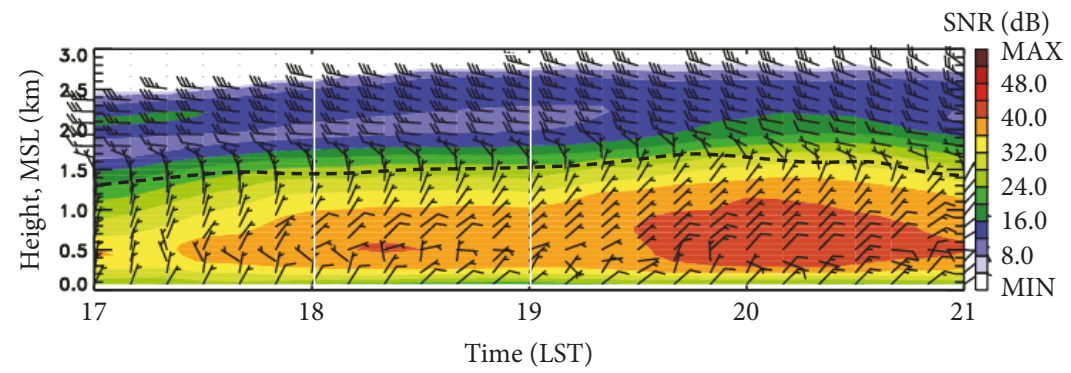

(b)

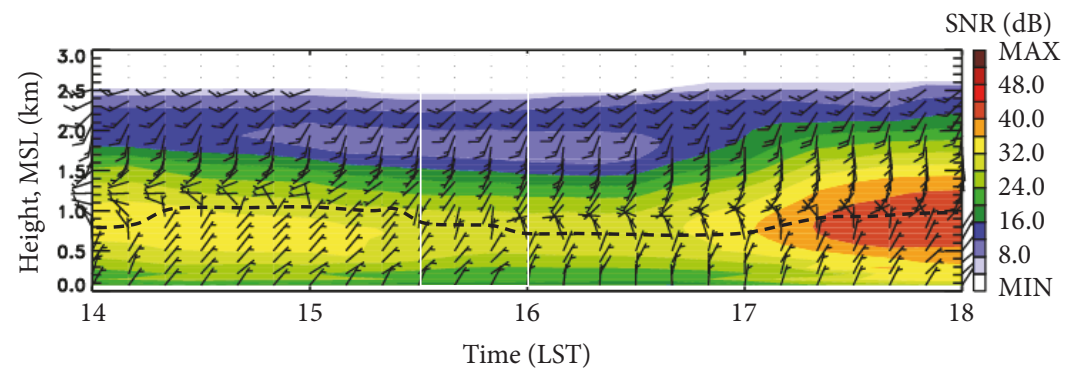

(c)

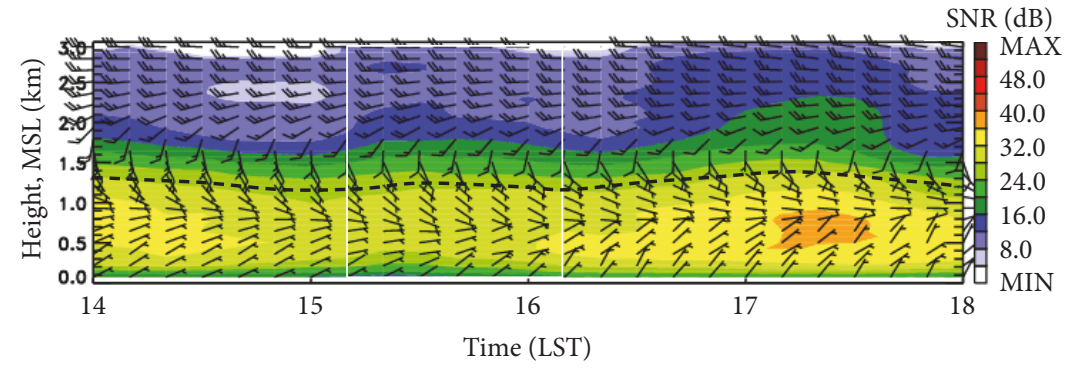

(d)

FIGURE 9: Time series of horizontal wind and the signal-to-noise ratio (SNR) of the wind profiler at GN for (a) EXP1, (b) EXP2, (c) EXP3, and (d) EXP4. The vertical solid lines mark the period of AgI generator operation at CPOS. The dashed line indicates the height of wind change. The details of each experiment are listed in Table 1.

microphysical and precipitation difference between NOSEED and Tot-SEED at YP after seeding. Finally, there was no snow depth measurement sensor that could be used to observe the actual snow accumulation before and after seeding at YP. The $0.5 \mathrm{~mm}$ tipping-bucket rain gauge used in this study only measured the snow melted by heating, and so the starting time of the increase in precipitation may be delayed. In addition, the actual ending time of the precipitation increase and the exact precipitation between 0.5 and $1.0 \mathrm{~mm}$ could not be determined due to the observational resolution of $0.5 \mathrm{~mm}$. However, if delayed, the appearance of precipitation increase at YP was within the Tot-SEED period.

To reduce the above-mentioned uncertainties, a snow depth meter was installed at YP in May 2015. Furthermore, a precipitation collector was developed to build a system for the analysis of the chemical composition of precipitation at 


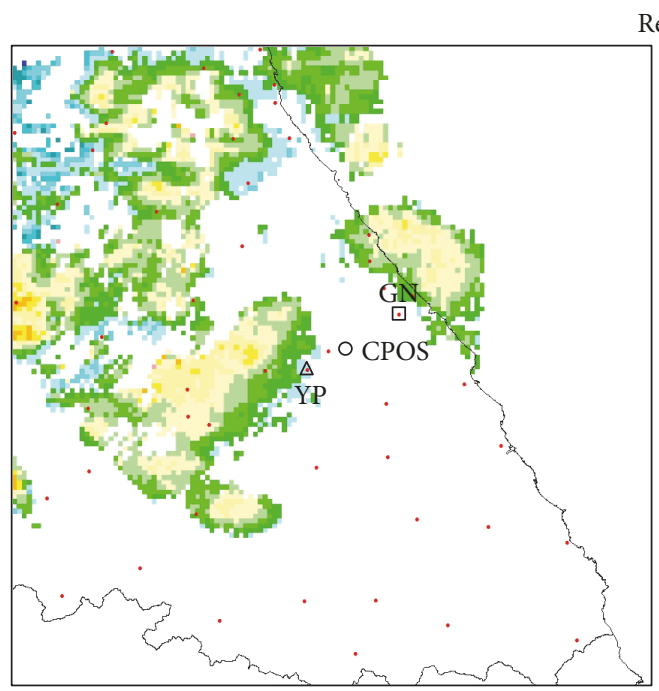

(a) 25 Feb. 2012 (EXP1)

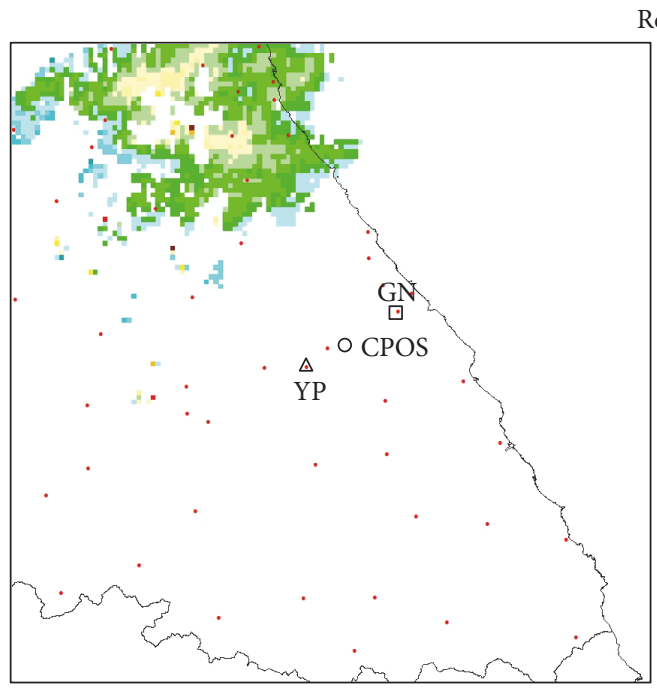

(c) 4 Jan. 2014 (EXP3)
Reflectivity (dBZ)

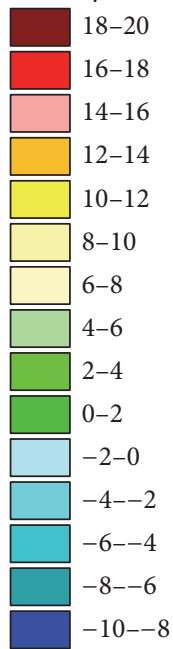

Reflectivity (dBZ)

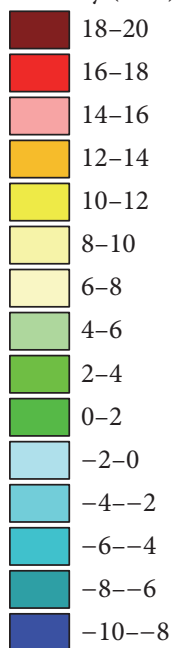

$-10-8$

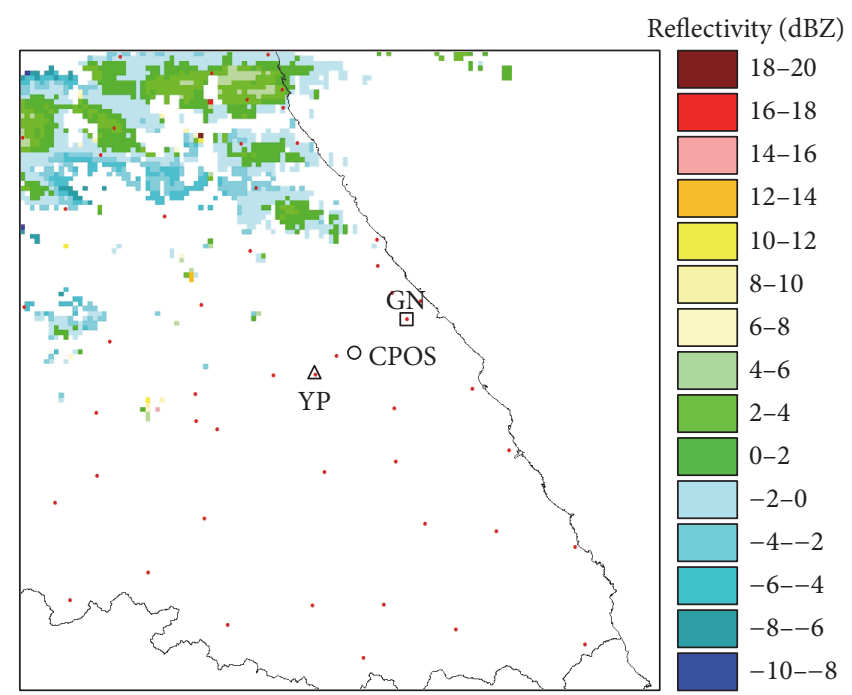

(b) 13 Mar. 2013 (EXP2)

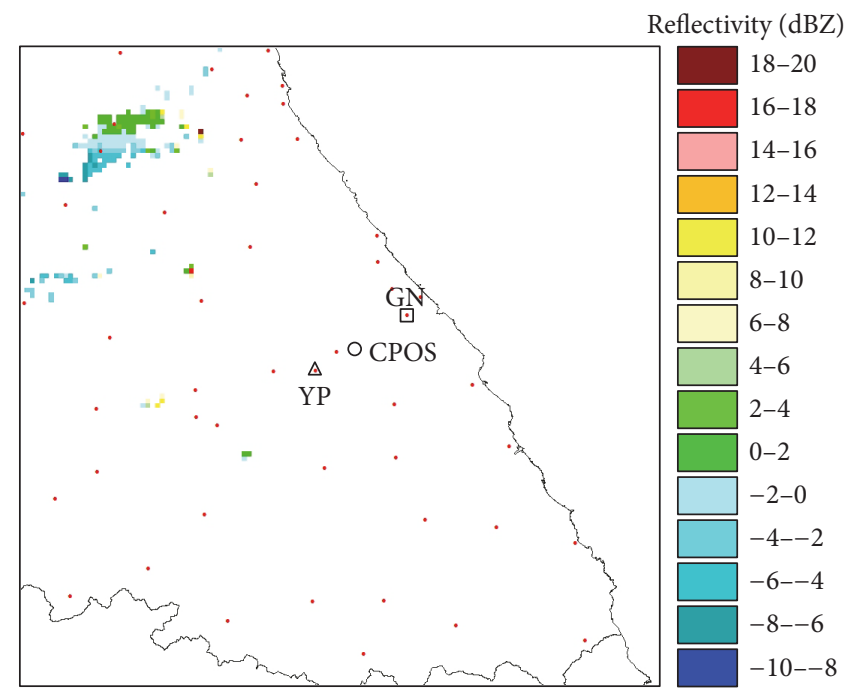

(d) 7 Apr. 2015 (EXP4)

FIGURE 10: The $1 \mathrm{~h}$ averaged composite reflectivity of PPI0 after the start of seeding from the Korea Meteorological Administration groundbased operating radars for (a) EXP1, (b) EXP2, (c) EXP3, and (d) EXP4. The red dot indicates the automatic weather station (AWS).

YP in March 2017. Many studies (e.g., [30-32]) have already addressed chemical verification for snow accumulation observed at the target region after seeding. In future experiments, more reliable verifications will be made by analyzing chemical changes in snow and precipitation. To complement these results, an intensive observation and seeding study will be carried out between November 2017 and January 2018 before the Winter Olympics in Pyeongchang.

\section{Disclosure}

An earlier version of this work was presented as a poster at Geophysical Research Abstracts Vol. 20, EGU2018-5930,
2018, EGU General Assembly 2018, and Korean Meteorological Society Fall Meeting, 2017.

\section{Conflicts of Interest}

The authors declare that they have no conflicts of interest.

\section{Acknowledgments}

This work was funded by the Korea Meteorological Administration Research and Development program "Research and Development for KMA Weather, Climate, and Earth System Services-Support to Use of Meteorological Information and 


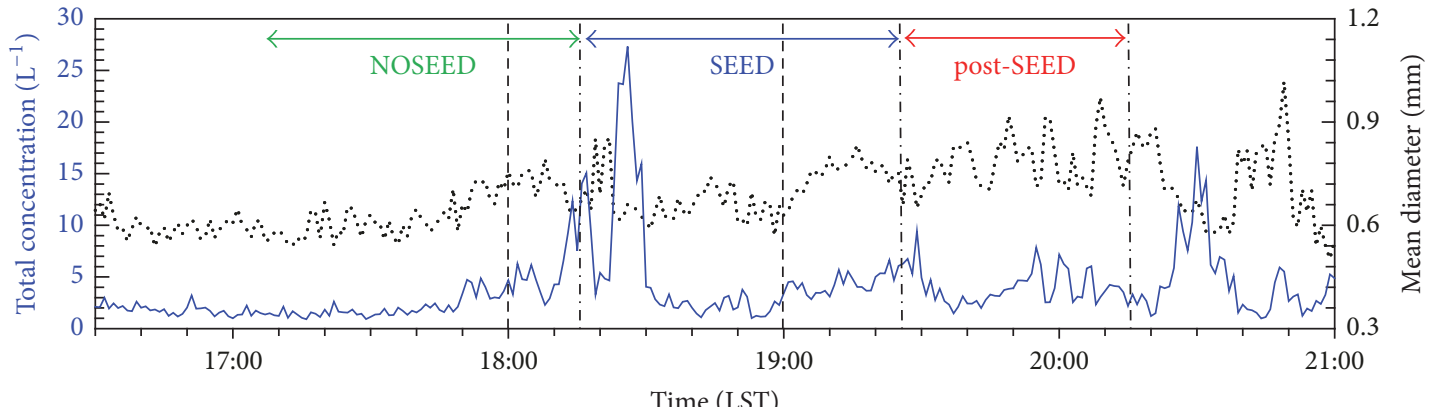

Time (LST)

mean diameter

— total concentration

(a)

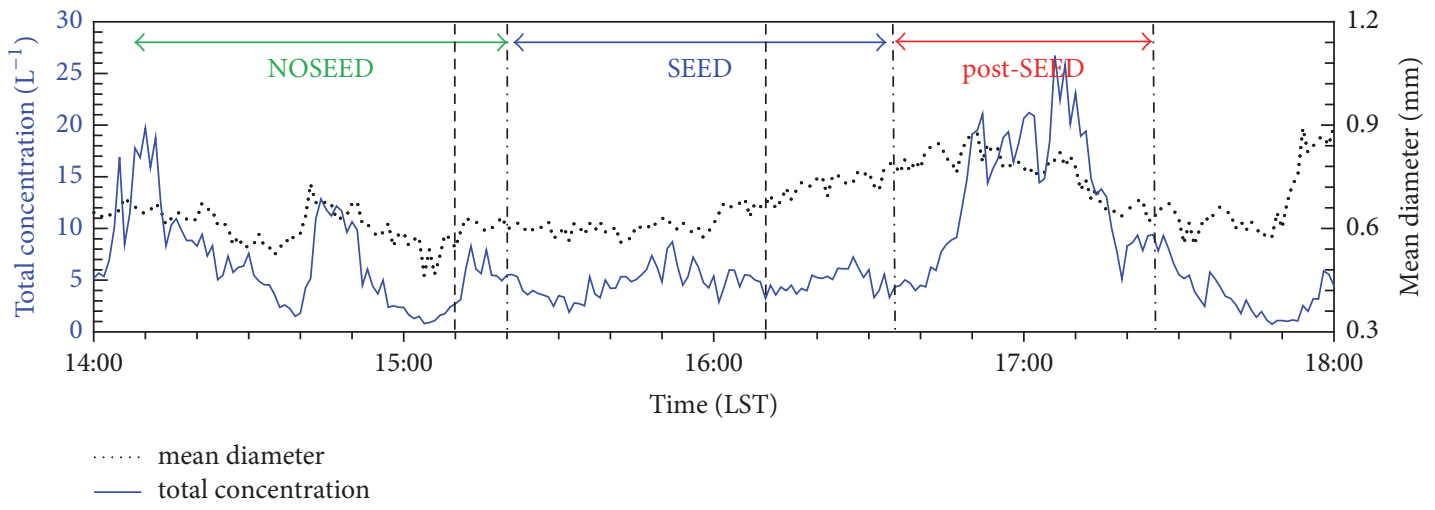

(b)

FIgure 11: Time series of snow size distribution obtained from the PARSIVEL at YP for (a) EXP2 and (b) EXP4. The dotted and solid lines indicate the mean diameter and total particle number concentrations of snow particles, respectively.

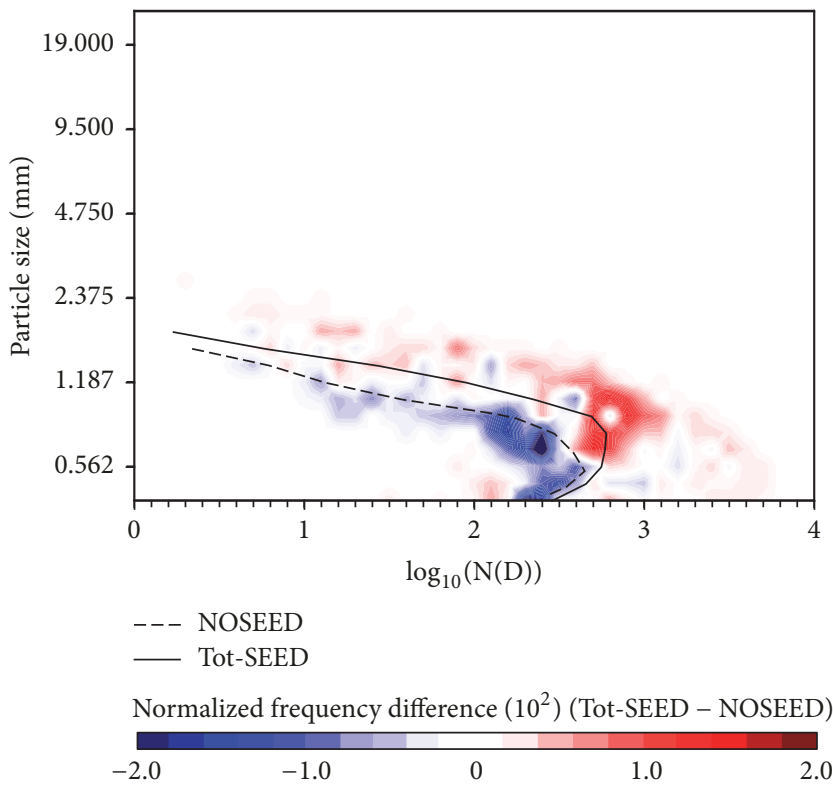

(a)

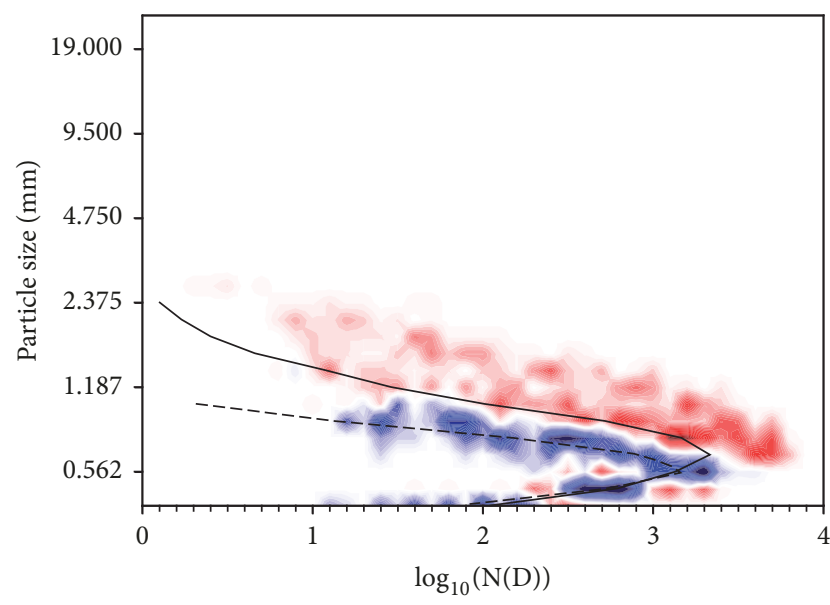

--- NOSEED

- Tot-SEED

Normalized frequency difference $\left(10^{2}\right)$ (Tot-SEED - NOSEED)

$-2.0$

$-1.0$

(b)

FIGURE 12: Normalized frequency difference from the PARSIVEL between NOSEED (dashed) and Tot-SEED (solid) at YP for (a) EXP2 and (b) EXP4. 
Value Creation" under Grant KMA2018-00222. The synoptic weather charts of the four cases were downloaded from the Korea Meteorological Administration website. The authors thank Professor Seong Soo Yum's team of Yonsei University for developing the WRF model with the modified Morrison scheme in microphysics.

\section{References}

[1] H. R. Pruppacher and J. D. Klett, Microphysics of Clouds And Precipitation, Kluwer Academic Publishers, Dordrecht, the Netherlands, 2010.

[2] V. J. Schaefer, "Final report project cirrus. Part I. Laboratory, field and flight experiments," Tech. Rep., General Electric Research Laboratory, Schenectady, NY, USA, 1953.

[3] R. T. Bruintjes, "A review of cloud seeding experiments to enhance precipitation and some new prospects," Bulletin of the American Meteorological Society, vol. 80, no. 5, pp. 805-820, 1999.

[4] I. Geresdi, L. Xue, and R. Rasmussen, "Evaluation of orographic cloud seeding using a bin microphysics scheme: twodimensional approach," Journal of Applied Meteorology and Climatology, vol. 56, no. 5, pp. 1443-1462, 2017.

[5] A. B. Super and J. A. Heimbach, "Microphysical effects of wintertime cloud seeding with silver iodide over the rocky mountains. Part II: observations over the bridger range, Montana," Journal of Applied Meteorology and Climatology, vol. 27, no. 10, pp. 1152-1165, 1988.

[6] A. B. Super and B. A. Boe, "Microphysical effects of wintertime cloud seeding with silver iodide over the rocky mountains. Part III: observations over the Grand Mesa, Colorado," Journal of Applied Meteorology and Climatology, vol. 27, no. 10, pp. 1166$1182,1988$.

[7] B. Geerts, Q. Miao, Y. Yang, R. Rasmussen, and D. Breed, “An airborne profiling radar study of the impact of glaciogenic cloud seeding on snowfall from winter orographic clouds," Journal of the Atmospheric Sciences, vol. 67, no. 10, pp. 3286-3302, 2010.

[8] B. Pokharel, B. Geerts, X. Jing, K. Friedrich, K. Ikeda, and R. Rasmussen, "A multi-sensor study of the impact of groundbased glaciogenic seeding on clouds and precipitation over mountains in Wyoming. Part II: seeding impact analysis," Atmospheric Research, vol. 183, pp. 42-57, 2017.

[9] M.-J. Lee, K.-H. Chang, G.-M. Park et al., "Preliminary results of the ground-based orographic snow enhancement experiment for the easterly cold fog (cloud) at Daegwallyeong during the 2006 winter," Advances in Atmospheric Sciences, vol. 26, no. 2, pp. 222-228, 2009.

[10] P. J. DeMott, "Quantitative descriptions of ice formation mechanisms of silver iodide-type aerosols," Atmospheric Research, vol. 38, no. 1-4, pp. 63-99, 1995.

[11] D. N. Blair, "Flame temperature effects on AgI nuclei produced from acetone generators," The Journal of Weather Modification, vol. 6, no. 1, pp. 238-245, 1974.

[12] W. C. Skamarock, J. B. Klemp, J. Dudhia et al., "A description of the advanced research WRF version 3," NCAR Technical Note NCAR/TN-475+STR, UCAR Staff Directory, New York, NY, USA, 2008.

[13] C. K. Kim, S. S. Yum, and Y.-S. Park, "A numerical study of winter orographic seeding experiments in Korea using the Weather Research and Forecasting model," Meteorology and Atmospheric Physics, vol. 128, no. 1, pp. 23-38, 2016.
[14] S. Chae, K. Chang, S. Seo et al., "Numerical Simulations of airborne glaciogenic cloud seeding using the WRF model with the modified morrison scheme over the Pyeongchang Region in the winter of 2016," Advances in Meteorology, vol. 2018, Article ID 8453460, pp. 1-15, 2018.

[15] B.-H. Heo, S. Jacoby-Koaly, K.-E. Kim, B. Campistron, B. Benech, and E.-S. Jung, "Use of the Doppler spectral width to improve the estimation of the convective boundary layer height from UHF wind profiler observations," Journal of Atmospheric and Oceanic Technology, vol. 20, no. 3, pp. 408-424, 2003.

[16] G. Ohring, S. Lord, J. Derber, K. Mitchell, and M. Ji, "Applications of satellite remote sensing in numerical weather and climate prediction," Advances in Space Research, vol. 30, no. 11, pp. 2433-2439, 2002.

[17] M. Löffler-Mang, "A laser-optical device for measuring cloud and drizzle drop size distributions," Meteorologische Zeitschrift, vol. 7, no. 2, pp. 53-62, 1998.

[18] M. Löffler-Mang and U. Blahak, "Estimation of the equivalent radar reflectivity factor from measured snow size spectra," Journal of Applied Meteorology and Climatology, vol. 40, no. 4, pp. 843-849, 2001

[19] M. Maahn and P. Kollias, "Improved Micro Rain Radar snow measurements using Doppler spectra post-processing," Atmospheric Measurement Techniques, vol. 5, no. 11, pp. 2661-2673, 2012.

[20] H. Yang, K. Chang, J. Cha, Y. Choi, and C. Ryu, "Characteristics of precipitable water vapor and liquid water path by microwave radiometer," Journal of the Korean Earth Science Society, vol. 33, no. 3, pp. 233-241, 2012 (Korean).

[21] S. Jung, Y. Lim, K. Kim, S. Han, and T. Kwon, "Characteristics of precipitation over the East Coast of Korea based on the special observation during the winter season of 2012," Journal of the Korean Earth Science Society, vol. 35, no. 1, pp. 41-53, 2014 (Korean).

[22] C.-K. Kim, S.-S. Yum, S.-N. Oh et al., "A feasibility study of winter orographic cloud seeding experiments in the Korean Peninsula," Asia-Pacific Journal of Atmospheric Sciences, vol. 41, no. 6, pp. 997-1014, 2005 (Korean).

[23] B.-C. Kwak and I.-H. Yoon, "Synoptic analysis on snowstorm occurred along the east coast of the Korean Peninsula during 5-7 January, 1997," Journal of the Korean Earth Science Society, vol. 21, no. 3, pp. 258-275, 2000 (Korean).

[24] J.-G. Lee, "Synoptic structure causing the difference in observed snowfall amount at Daegwallyeong and Gangnung: case study," Asia-Pacific Journal of Atmospheric Sciences, vol. 35, no. 3, pp. 321-334, 1999.

[25] G. Vali, D. Rogers, G. Gordon et al., "Aerosol and nucleation research in support of NASA cloud physics experiments in space," Final Report NAS8-32067, 1978.

[26] L. Xue, S. A. Tessendorf, E. Nelson et al., "Implementation of a silver iodide cloud-seeding parameterization in WRF. Part II: 3D simulations of actual seeding events and sensitivity tests," Journal of Applied Meteorology and Climatology, vol. 52, no. 6, pp. 1458-1476, 2013.

[27] S. E. Yuter and R. A. Houze, "Three-dimensional kinematic and microphysical evolution of florida cumulonimbus. Part II: Frequency distributions of vertical velocity, reflectivity, and differential reflectivity," Monthly Weather Review, vol. 123, no. 7, pp. 1941-1963, 1995.

[28] B. Pokharel, B. Geerts, and X. Jing, "The impact of ground-based glaciogenic seeding on orographic clouds and precipitation: 
a multisensor case study," Journal of Applied Meteorology and Climatology, vol. 53, no. 4, pp. 890-909, 2014.

[29] B. Pokharel, B. Geerts, X. Jing et al., "The impact of groundbased glaciogenic seeding on clouds and precipitation over mountains: a multi-sensor case study of shallow precipitating orographic cumuli," Atmospheric Research, vol. 147-148, pp. 162182, 2014.

[30] B. Pokharel, B. Geerts, and X. Jing, "The impact of groundbased glaciogenic seeding on clouds and precipitation over mountains: A case study of a shallow orographic cloud with large supercooled droplets," Journal of Geophysical Research: Atmospheres, vol. 120, no. 12, pp. 6056-6079, 2015.

[31] J. M. Fisher, M. L. Lytle, M. L. Kunkel et al., "Evaluation of glaciogenic cloud seeding using trace chemistry," The Journal of Weather Modification, vol. 48, pp. 24-42, 2016.

[32] A. Zipori, D. Rosenfeld, J. Shpund, D. M. Steinberg, and Y. Erel, "Targeting and impacts of AgI cloud seeding based on rain chemical composition and cloud top phase characterization," Atmospheric Research, vol. 114-115, pp. 119-130, 2012. 

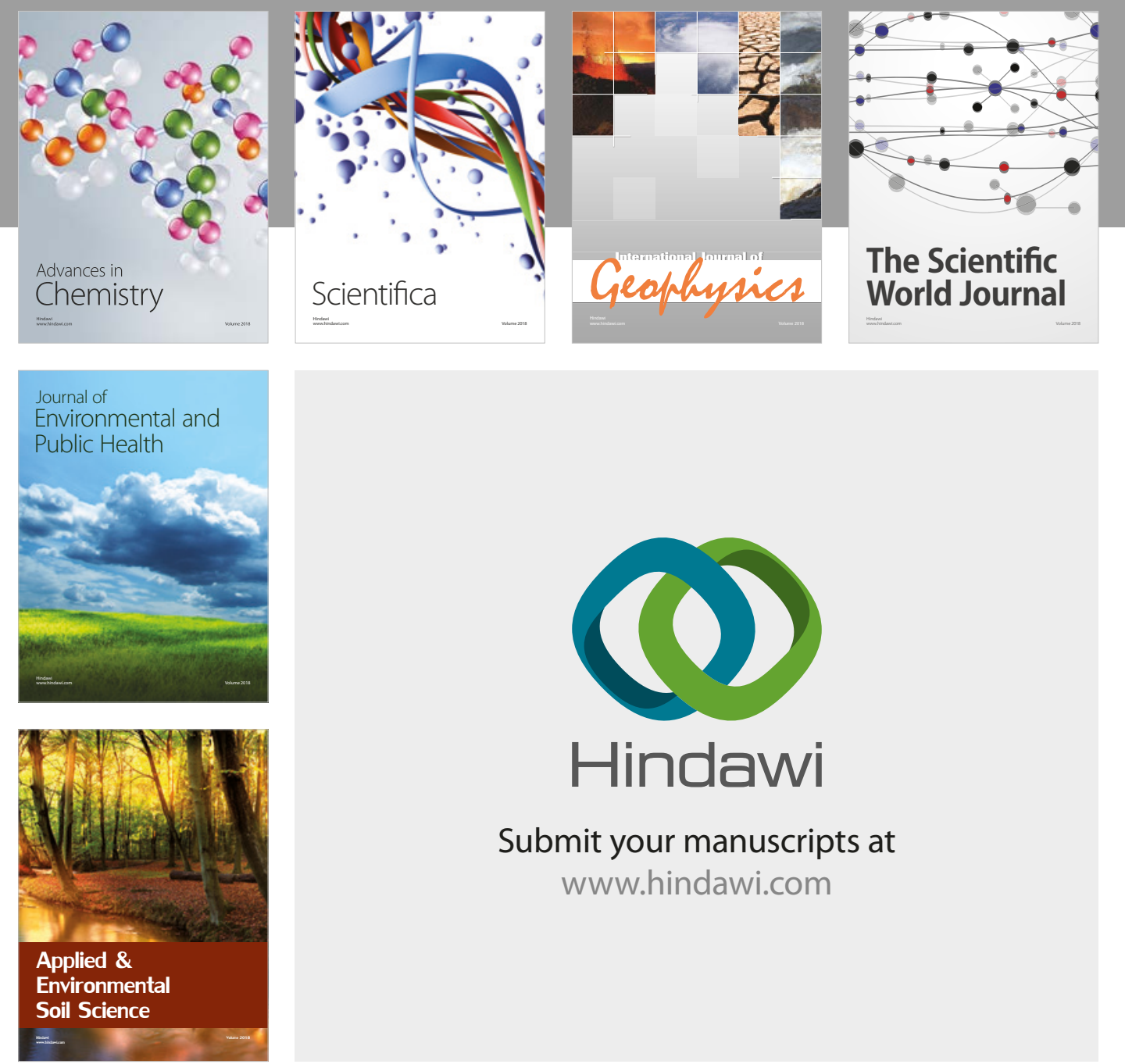

The Scientific

\section{World Journal}
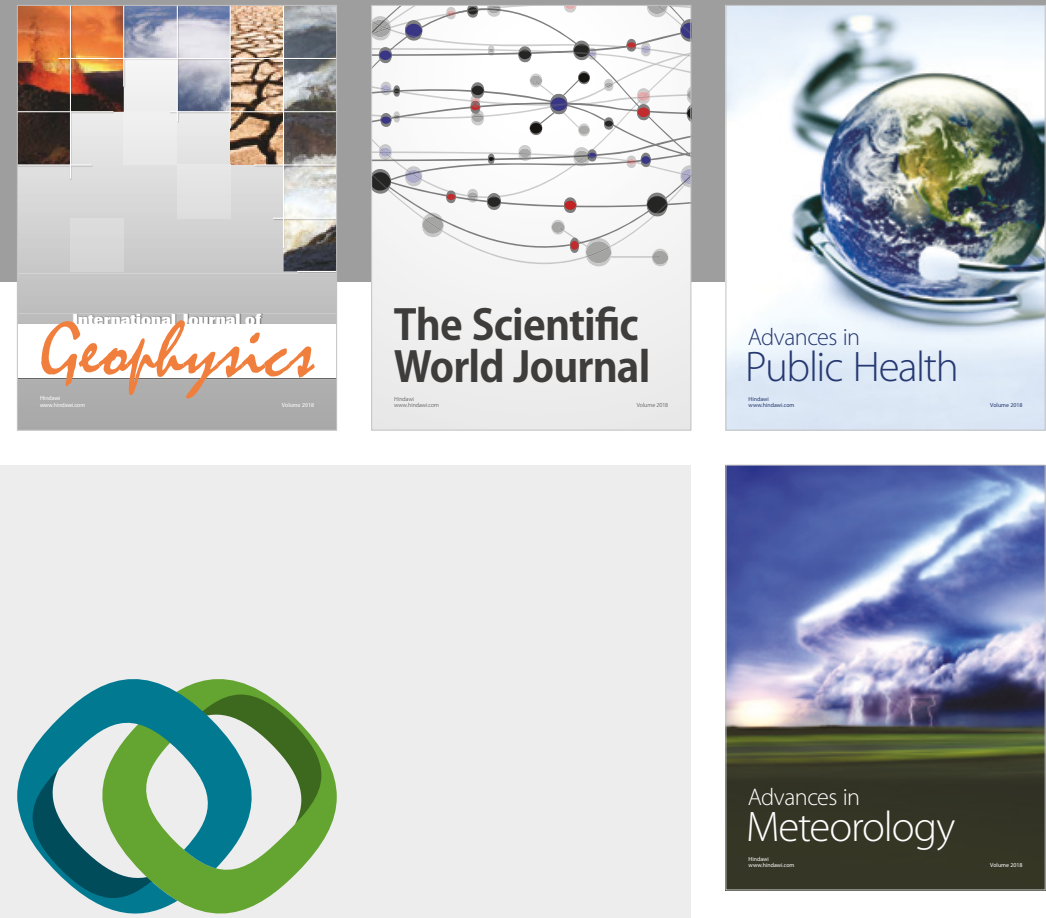

Advan

Public Health

\section{Hindawi}

Submit your manuscripts at

www.hindawi.com
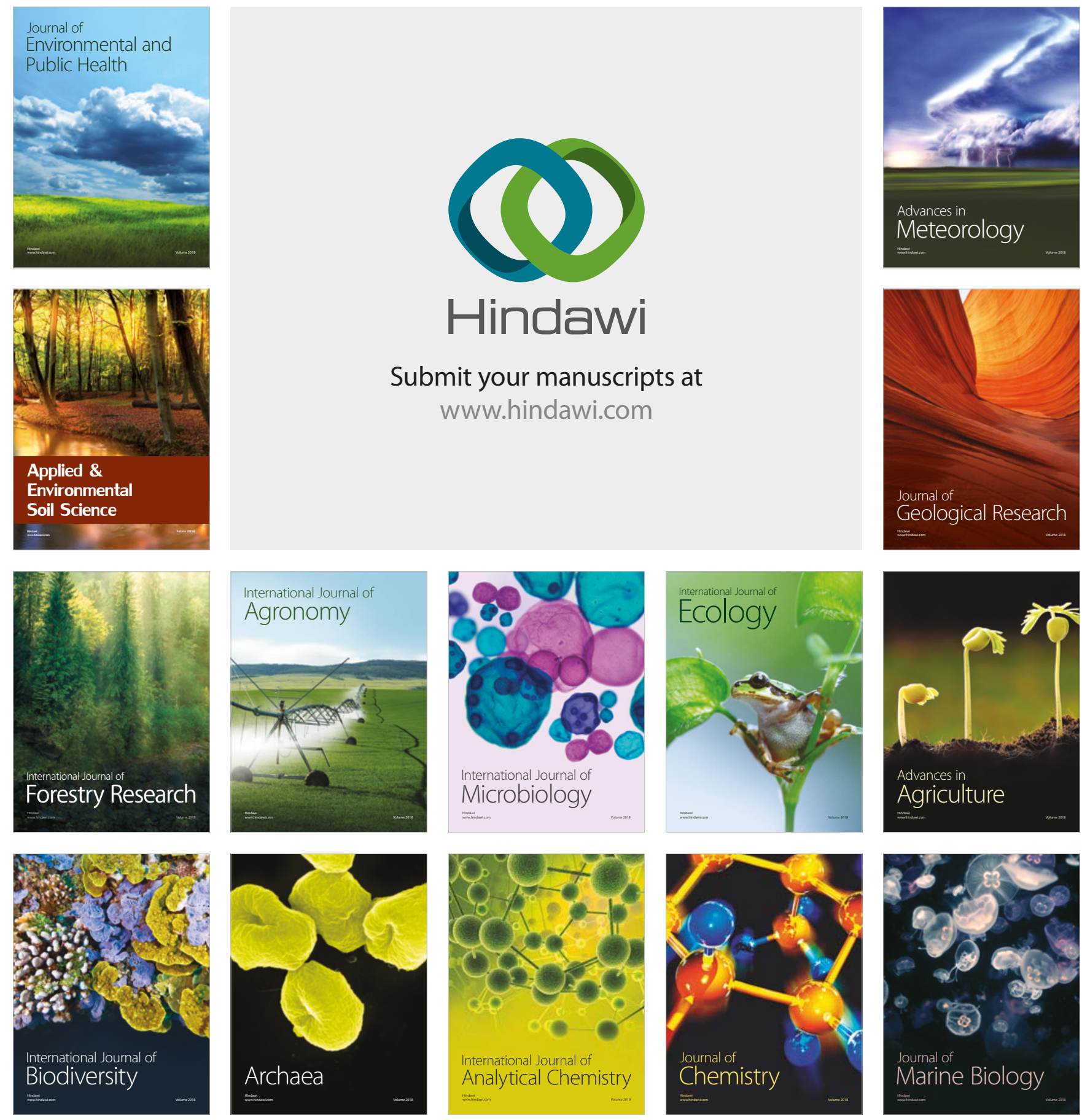